\title{
RECENT ADVANCES AND PROSPECTS OF SQUARE-WAVE VOLTAMMETRY
}

\author{
Valentin Mirčeski ${ }^{1,2, *}$, Leon Stojanov ${ }^{1}$, Sławomira Skrzypek ${ }^{2}$ \\ ${ }^{1}$ Institute of Chemistry, Faculty of Natural Sciences and Mathematics \\ Ss. Cyril and Methodius University, Skopje, Republic of Macedonia \\ ${ }^{2}$ Department of Inorganic and Analytical Chemistry, Faculty of Chemistry, \\ University of Lódż, Poland \\ *e-mail: valentin@pmf.ukim.mk
}

\begin{abstract}
This review concerns recent methodological advances of square-wave voltammetry as one of the most sophisticated members of the pulse voltammetric techniques. Besides addressing recent theoretical works and representatives of advanced analytical studies, an emphasis is given to a few novel methodological concepts such as kinetic analysis at constant scan rate, cyclic square-wave voltammetry, multisampling square-wave voltammetry, and electrochemical faradaic spectroscopy. For the purpose of improving analytical performances of the technique two new methods are proposed for the first time.
\end{abstract}

Key words: square-wave voltammetry; electrode mechanisms; electrode kinetics

\section{INTRODUCTION}

Square-wave voltammetry (SWV) is a wellknown and versatile voltammetric technique for analytical application, mechanistic studies and kinetic measurements of electrode processes [1-3]. It is a member of the large family of pulse voltammetric techniques, and it can be considered as a special form of the popular differential pulse voltammetry [4]. In a historical perspective the technique originates from the Kalousek commutator [5] and Barker square-wave polarography [6-8]. The popularity of the technique has been permanently increasing since the seminal work of Osteryoungs [9, 10], remarkable theoretical work of Lovrić [11] and contributions of others [12-24]. Methodological development and application of the technique have been reviewed over the years [25-36] and two specialized monographs are exclusively dedicated to SWV $[1,37]$.

Basic features of the potential modulation, together with the simulated response in the course of experiment, are depicted in Figure 1. In the contemporary SWV, the potential modulation comprises of a staircase potential combined with square-shaped potential pulses (Figure 1A), which was first intro- duced by Ramaley and Krause [38, 39]. The main parameters of the potential cycle, composed of two neighbouring pulses (Figure 1B), are the height of the pulses (referred to as SW amplitude, $E_{s w}$ ) and the duration of the single potential cycle $\tau$ (Figure 1B). Commonly, the duration of a potential cycle is expressed in terms of SW frequency $(f)$, defined as $f=1 / \tau$. In terms of the duration of a potential pulse $t_{\mathrm{p}}\left(\tau=2 t_{p}\right)$, the frequency could be defined as $f=$ $1 /\left(2 t_{p}\right)$. The physical meaning of the frequency, as critical time parameter, can be understood as a number of potential cycles in a unit of time. Besides, the scan rate of the overall experiment can be defined as $v=f \Delta E$, where $\Delta E$ is the step of the staircase potential (cf. Figure 1B).

Relative to the direction of the staircase modulation, forward and reverse (backward) potential pulses can be distinguished. In the course of each potential cycle the electrode reaction is driven in both anodic and cathodic directions by the two opposite pulses, thus providing an insight into the electrode mechanism. In the course of the experiment, the current varies with time as theoretically predicted in Figure 1C. However, it is not the real outcome 
of the experiment as the current sampling is done at the end of each potential pulse only, aiming to discriminate against the charging current $[1,10]$. The forward $\left(I_{f}\right)$ and backward (reverse) $\left(I_{r}\right)$ component of the SW voltammogram (Figure 1D) correspond to the currents associated to the forward and backward potential pulses, respectively (cf. Figure 1C). An important feature of the SW voltammetric response is that both forward and backward components are plotted versus the potential of the staircase modulation, i.e. the mid potential of the two adjoining pulses (cf. Figure 1B). For these reasons two current values are assigned to each potential value of the staircase modulation. The net SW component $\left(I_{\text {net }}\right)$ (cf. Figure 1D) is calculated by subtracting the backward from the forward currents, which most frequently is a bell- shaped curve, enabling precise determination of the position $\left(E_{p}-\right.$ net peak potential) and the height (net peak current $\Delta I_{p}$ ) (Figure 1D).

Besides addressing recent representative examples from the field of theory and analytical application of the technique, the current review focuses mainly on the methodological development achieved in the last several years. A few promising methods in the direction of expanding and facilitating the application of the technique for mechanistic and kinetic analysis of electrode processes are addressed. In the end, for the purpose of improving analytical performances of the technique two new methodological concepts are elaborate briefly for the first time.
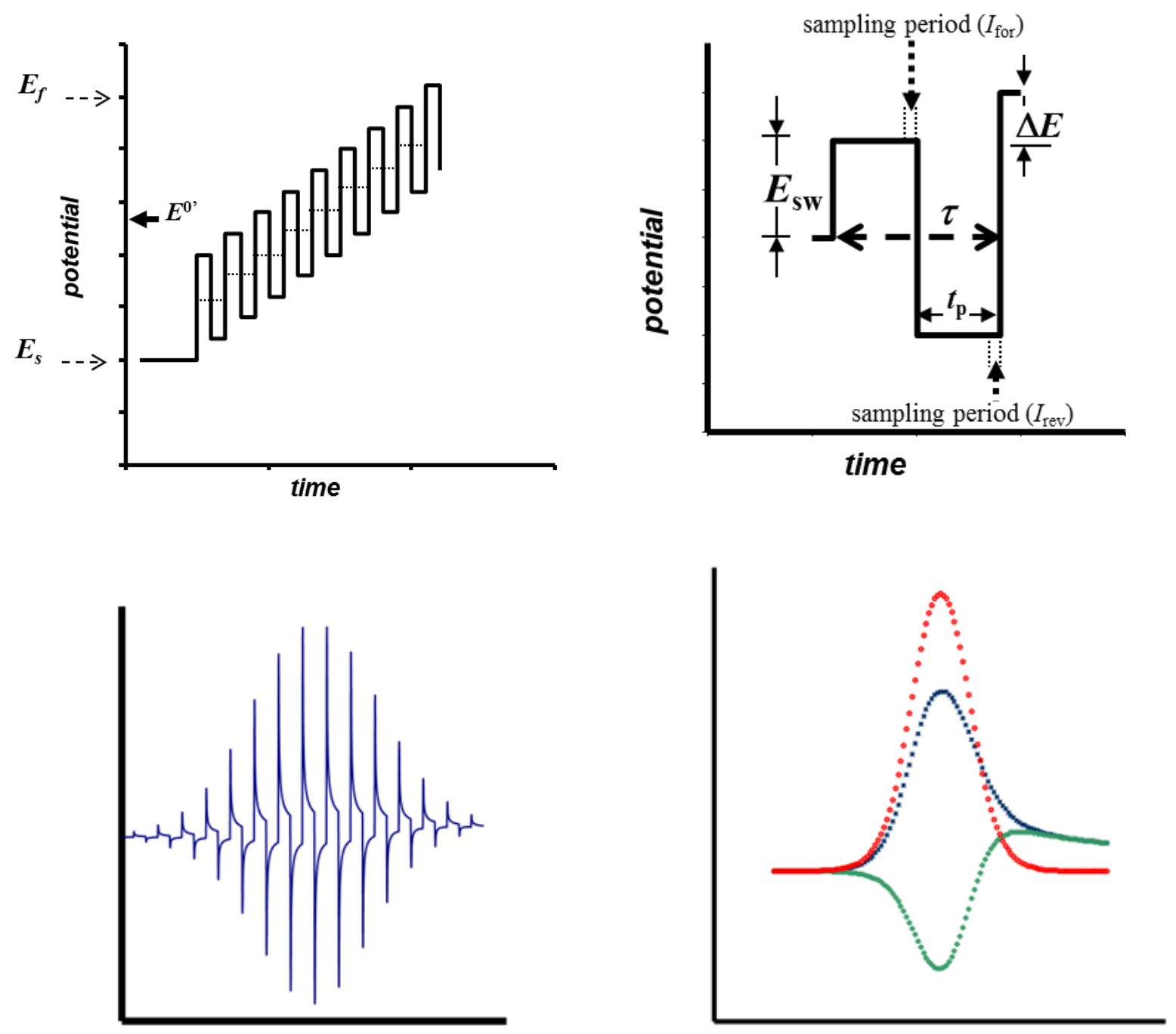

Figure 1. (A) Potential modulation in square-wave voltammetry; (B) Single potential cycle in square-wave voltammetry; (C) Variation of the current in the course of the square-wave voltammetry; (D) Typical square-wave voltammogram consisting of forward $\left(\Psi_{f}\right)$, reverse $\left(\Psi_{r}\right)$ and net component $\left(\Psi_{n e t}\right)$. 


\section{ELECTRODE MECHANISMS AND ANALYTICAL APPLICATIONS}

A variety of electrode mechanisms have been analyzed applying SWV in the past several years. In general, the advances in the theory of pulse voltammetric techniques, including SWV, can be found in the mini review of Molina et al. [40]. Electrode mechanism including three electrode reactions coupled with two chemical reactions (ECECE mechanism) was developed by Lovrić [41], building up on the previous theoretical study of three-step electrode reaction [42]. In [41] three reversible electrode reactions that are connected by two reversible chemical reactions have been considered, with emphasize on the influence of the basic thermodynamic parameters. Lovrić also developed theoretical model of an electrode process of amalgam forming ions at spherical electrodes [43], as well as the theory of an electrode reaction followed by the dimerization of the product [44].

Fatouros and Krulic analyzed specific conditions when the responses under conditions of pulse voltammetry and linear scan voltammetry match [45]. It has been shown that the forward component of the SW voltammetric response of a reversible electrode reaction of a solution resident redox couple at a macroscopic electrode under certain experimental conditions can match with the response of simple linear sweep voltammetry.

Molina et al. discussed the effects of unequal diffusion coefficients and coupled chemical equilibria on the SWV response at disc and hemispherical microelectrodes [46]. It has been pointed out that under non-steady-state conditions the case of unequal diffusion coefficients gives rise to a complex behaviour of the SW voltammetric response, being significantly different from the theoretical predictions established under the assumption of equal diffusion coefficients.

Vettorelo and Garay developed a theory of complex and important electrode system coupled with adsorption and regenerative catalytic reaction [47], proposing diagnostic criteria for characterisation of the experimental system, while Garcia-Araez et al. proposed simple and efficient procedure for measuring the rate of transport of redox species through membranes by using SWV [48]. SWV has been applied by Rama Kant to analyze theoretically the response at rough electrodes [49]. An explicit mathematical expression is proposed relating the staircase, cyclic staircase, differential pulse, and square-wave voltammetric response of finite fractal electrode to the statistical morphological characteristics.

There exist numerous analytically oriented studies including SWV and their full citation is vir- tually impossible, thus only a few representative examples will be briefly mentioned. A useful collection of references on the analytical application of SWV can be found in the recent reviews on electrochemical sensors for forensic drug analysis [50], application of bismuth electrodes in contemporary electroanalysis [51], electrochemical biosensors [52], and electrochemical methods for determination of the antioxidant capacity of food [53]. Cao et al. presented an advanced state-of-the-art strategy for multi-antibiotics detection using SWV [54]. The same authors presented dual-signalling electrochemical aptasensor using ferrocene and $\left[\mathrm{Ru}\left(\mathrm{NH}_{3}\right)_{6}\right]^{3+}$ as two signal indicators, quantified with SWV, reaching subpicomolar limit of detection [55]. Sedova et al. studied complex kinetic and thermodynamic behaviour of strand displacement at the electrode surface in detection of single base mismatches [56]. In the mechanistically oriented study, where SWV was used as an electroanalytical tool for detection of a redox label, they have found a complex interplay between the position of the redox label, variations in strand displacement kinetics, and alterations in the melting temperature of DNA duplexes tethered on the gold surface. D'Eramo et al. reported on the application of SWV for simultaneous determination of eugenol, thymol and carvacrol (CA) in honey samples at a glassy carbon electrode [57]. Taleb et al. [58] reported on the preparation of electrochemical sensor using self-organized gold nanoparticle modified highly oriented pyrolytic graphite electrode, which was applied for the analysis of copper and silver ions with SWV. The sensor exhibited remarkable performances in terms of preparation, simplicity, and detection limit. Finally, Domenech-Carbó et al. [59] reported on an important application of SWV in the solid-state electrochemistry of organosulfur compounds existing in petroleum and its derived matrices according to the methodology of the voltammetry of immobilized microparticles.

\section{RECENT METHODOLOGICAL ADVANCES OF SWV}

\section{Kinetic analysis at a constant scan rate}

Commonly, kinetic analysis in voltammetry is performed by changing the scan rate, which affects the critical time of the voltammetric experiment. As previously mentioned, the frequency $(f)$ is the critical time parameter in SWV (cf. Figure 1B). Adjusting the frequency one defines the available time to drive the electrode reaction in both cathodic and anodic directions at a given potential. Hence, all intrinsic kinetic parameters controlling the response are frequency related; e.g. for a quasireversible electrode reaction of a solution resident redox couple 
$\mathrm{Ox} /$ Red the electrode kinetic parameter is $\kappa=\frac{k_{s}}{\sqrt{D f}}[1]$, where $k_{s}$ is the formal rate constant and $D$ is the common diffusion coefficient of both Ox and Red. For an electrode mechanisms coupled with chemical reactions (e.g. EC, CE, EC' etc.) addition chemical kinetic parameter appears, defined as $\lambda=\frac{k_{c}}{f}$, where $k_{c}$ is the first order rate constant of the coupled chemical reaction [1]. Thus, variation of the frequency affects particular kinetic parameter, which is the basic of the methodology for estimation of kinetic rate constants. However, the system is frequently affected by several parameters and the frequency exhibits a complex influence, making the estimation of the rate constants tedious.

To circumvent the latter complexity, a simple methodology has been developed for kinetic analysis at a constant scan rate, i.e. at constant frequency, taking advantage of the pulse height (amplitude $\left(E_{s w}\right)$ ) [60]. Let us first note that during a single potential pulse (cf. Figure 1B) the actual sampling of the forward $\left(I_{f}\right)$ and reverse $\left(I_{r}\right)$ currents is done at the potentials of the forward and reverse pulse, respectively, which differ between each other for the absolute potential value of $2 E_{s w}$. Thus, the actual driving force is the sum of the potential of the step and the amplitude. This implies the electrode kinetics can be significantly affected by the amplitude only, while keeping the frequency constant. The latter provides significant advantage in the kinetic analysis, as the comparison of the experimental and theoretical voltammograms is simplified to a large extend when all frequency related kinetic parameters are kept constant.

This is the basis of the simple methodology for electrode kinetic measurement by analyzing the peak potential separation of the forward and reverse SW voltammetric components as a function of the amplitude [61]. Indeed, the methodology was introduced for the first time almost two decades ago [62], by considering only fast surface confined electrode reactions, which are attributed with net peak splitting. The method was recently generalized by considering electrode processes of a solution resident redox couple [61], as well as stripping electrode mechanisms. Experimental conformation was done for both surface confined electrode processes [63] and a dissolved redox couple [61]. It is further expected to challenge this simple approach for mechanisms coupled with chemical reactions.

Figure 2 illustrates the evolution of the forward and backward SW components of a surface confined electrode reaction by increasing the amplitude. The electrode reaction is attributed with the electrode kinetic parameter, $\omega=\frac{k_{\text {sur }}}{f}$ where $k_{\text {sur }}$ is the formal rate constant of the electrode reaction expressed in units of $\mathrm{s}^{-1}$. The increasing amplitude causes an enhancement of both the intensity and peak potential separation of the response. The inset of the Figure 2A displays the peak potential separation $\left(\Delta E_{p}\right)$ as a function of the electron-normalized amplitude $\left(n E_{s w}\right)$ for different electrode kinetic parameters. The data clearly imply that the studied feature is sensitive to the electrode kinetics enabling estimation of the formal rate constant. The original method was further developed by the recent contribution of Bonazzola and Gordillo for the electrode kinetics of surface confined processes [64].

At this point, it is however useful to note that besides the electrode kinetics, the peak potential separation is partly consequence of the conventional way of presenting the data in SWV, where the forward and reverse voltammetric components are plotted vs. the potential of the staircase modulation, though they are measured at respective potentials of potential pulses. To avoid this artefact in the kinetic analysis we have recently introduced the so called "potential corrected SW voltammograms" [61]. Indeed, in the latter variant of SWV only the forward and reverse components are considered, avoiding the net SW components, which are plotted vs. the real potentials of the pulses, instead of being plotted versus the potentials of the staircase potential modulation. Such simple correction can be easily done to any SW voltammograms by appropriate shift of the forward and reverse components for the value of the SW amplitude along the potential axis, as shown in Figure 2B. In potential corrected SW voltammograms, the peak potential separation bares information on the electrode kinetics only [61].

Besides the peak potential separation, the SW amplitude can be related to the peak currents of all three components of the response [65]. As shown in Figure 3, the morphology of the response depends dramatically on the SW amplitude, in terms of the peak current ratio of the forward and backward components, exemplified with the quasireversible electrode reaction of a solution resident redox couple. Whether electrode reaction appears as an irreversible process (Figure $3 \mathrm{~A}-(1)$ ), or as a relatively fast quasireversible process (Figure 3A-(3)), depends markedly on the amplitude. This phenomenon was studied in detail revealing that the kinetic regions of the electrode reaction depend strongly on the amplitude. Figure 3B displays typical variation of the dimensionless net-peak current with the electrode kinetic parameter of the electrode reaction of a dissolved redox couple. Note the linearly increasing part of the curves is associated to the typical quasi- 
revesible behaviour of the reaction [1]. Obviously, the quasireversible kinetic interval depends strongly on the amplitude, being shifted toward lower values at higher amplitudes (cf. Figure 3B). In other words, large amplitude provides sufficient driving force to make intrinsically slow electrode processes relatively fast. Thus, increasing the amplitude enables kinetic estimation of slow electrode processes [65].
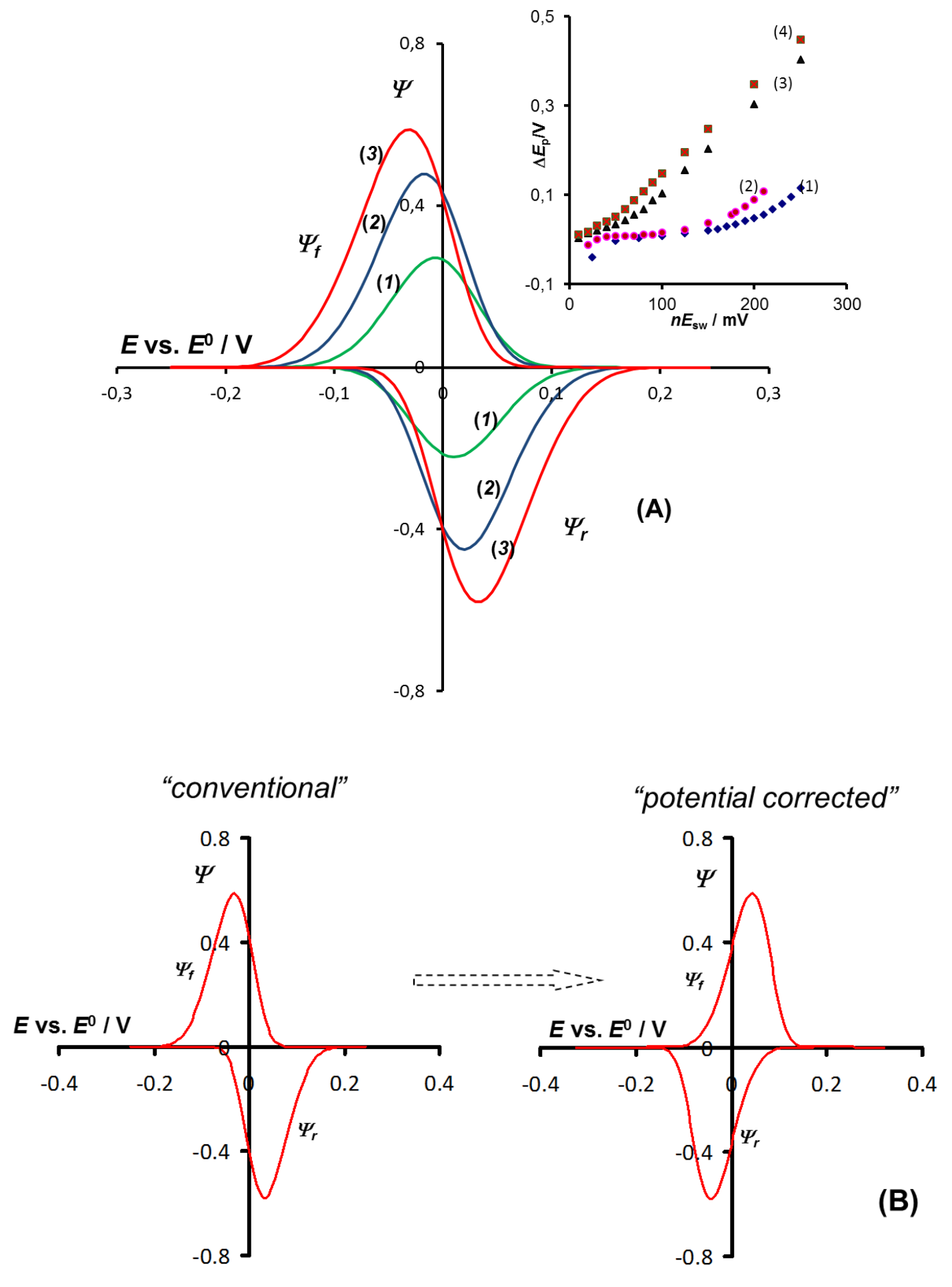

Fig. 2. Quasireversible electrode reaction of a surface confined redox couple. (A) Evolution of the simulated forward and reverse SW components with increasing amplitude of the potential modulation of $n E_{\mathrm{sw}}=25(1) ; 50$ (2) and $75 \mathrm{mV}(3)$. The other conditions of simulations are: electrode kinetic parameter $\omega=1$, electron transfer coefficient $\alpha=0.5$, and scan increment $\Delta E=5 \mathrm{mV}$. The inset shows the dependence of the peak potentials separation on the $\mathrm{SW}$ amplitude for electrode kinetic parameter of $\omega=0.05$ (1); 0.1 (2); 1 (3) and 2 (4). (B) Conventional and potential corrected SW voltammogram showing the forward and reverse components for conditions corresponding to curve (3) in panel (A). 

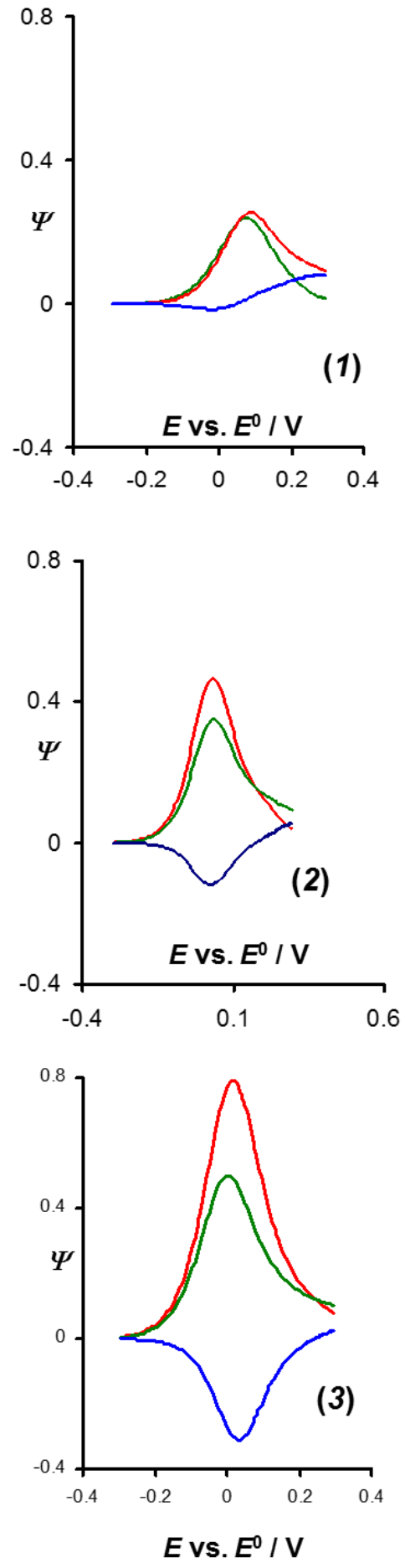

(A)

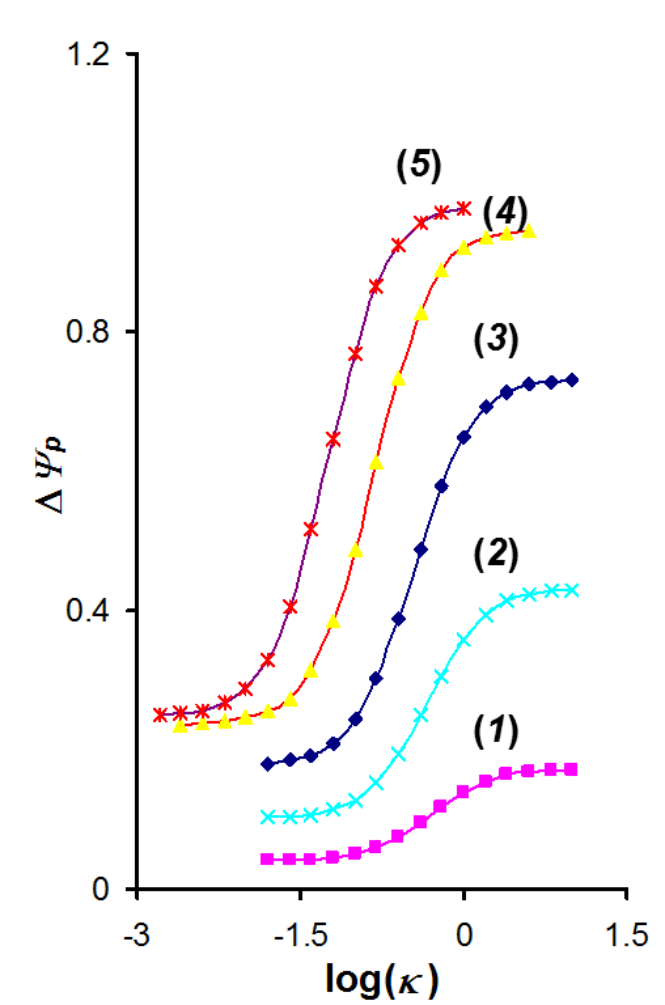

(B)

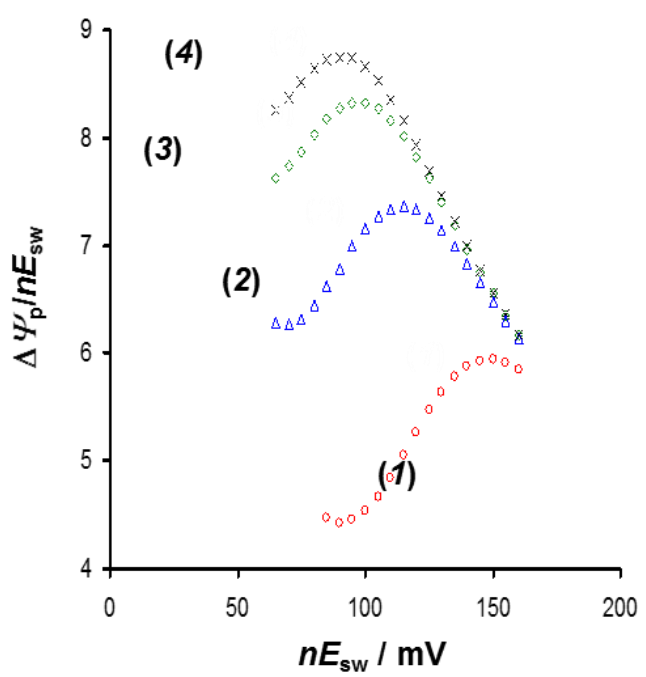

(C)

Figure 3. Quasireversible electrode reaction of a dissolved redox couple at a planar electrode. (A) The evolution of the simulated SW voltammograms at different amplitudes of $E_{\mathrm{sw}}=60(1), 120(2)$ and $180 \mathrm{mV}$ (3). Conditions of the simulations are: electrode kinetic parameter $\kappa=0.06$, electron transfer coefficient $\alpha=0.5$, stoichiometric number of electrons $n=1$, and scan increment $\Delta E=5 \mathrm{mV}$. (B) The dependence of the dimensionless net peak current on the logarithm of the electrode kinetic parameter for different amplitudes. The conditions of the simulations are: $E_{\mathrm{sw}}=10$ (1); 25 (2); 50 (3); 100 (4) and $150 \mathrm{mV}(5)$.

(C) The dependence of the amplitude-based quasireversible maximum on the electrode kinetic parameter. Simulations are conducted for $n=2$ and $\kappa=0.01(1) ; 0.03(2) ; 0.05(3)$ and $0.06(4)$. 
Foregoing theoretical considerations provides a basis for development of a new kinetic method by means of the analysis of the net-peak currentamplitude relation. Interestingly, Figure $3 \mathrm{C}$ shows that the ratio of the net peak current and the electron-normalized amplitude $\left(\Delta \Psi_{p} / n E_{s w}\right)$ is a parabolic function of the amplitude, for a single electrode reaction. This feature was termed as amplitude-based quasireversible maximum, by analogy to the wellknown quasireversible maximum of surface confined or adsorption complicated electrode processes $[1,11]$. The position of the amplitude-based quasireversible maximum is sensitive to the electrode kinetics enabling estimation of the formal rate constant in a simple, fast and efficient procedure. Unlike the conventional quasireversible maximum, the amplitude-based quasireversible maximum is not limited to adsorption complicated electrode processes, rather than it is a general feature of a broad class of electrode mechanisms. The methodology was experimentally supported with a variety of electrode mechanisms including 2-methyl-2-nitropropane [65], alizarine, vitamin B12 and vitamin K2 [63].

Finally, it is worth mentioning that a possible drawback of both amplitude-based methodologies is related to the fact that by using large amplitude values, i.e. $E_{s w}>150 \mathrm{mV}$ ) distortions of the experimental curves are possible due to significant contribution of the charging current, which has to be considered in the course of the real experimental analysis.

Approaching slow electrode processes - the role of the step potential increment in SWV

As previously mentioned, the main time parameter in SWV is the frequency, with the typical interval values provided by the modern instrumentation from 5 to $2000 \mathrm{~Hz}$. For the minimal frequency of $5 \mathrm{~Hz}$ one gets the maximal duration of a single potential cycle, $\tau=200 \mathrm{~ms}(\tau=1 / f)$, revealing that one deals with intrinsically fast technique. The latter could be considered as a drawback when slow electrode processes are considered (unfortunately the majority of electrode reactions are relatively sluggish). In the previous section, (Kinetic analysis at a constant scan rate), it was revealed that kinetics of the electrode reaction, i.e., the electrochemical reversibility, can be significantly affected by increasing the amplitude, transforming intrinsically slow processes in electrochemically quasireversible reactions (cf. Figure 3). However, besides the amplitude, in a quest to analyze slow electrode processes there could be another tool in hand; it is the step potential increment $\Delta E$ of the staircase potential modulation (cf. Figures 1A and B). The latter assumption stem from the expectation that along the frequency the electrochemical reversibility depends on the overall scan rate defined as $v=\Delta E f$. Unfortunately, there is a gap in the theory of SWV regarding the role of the step potential increment and the overall scan rate in the electrochemical reversibility. Jadresko et al. [66] studied the effect of the scan rate in SWV and staircase voltammetry for the case of reversible electrode processes of a solution resident redox couple, however the analysis of quasireversible electrode mechanisms is still missing. For these reasons, we illustrate briefly the effect of the step potential increment, in order to emphasize the potential usage in studying electrode kinetics.

Figure 4A illustrates how the step potential increment affects profoundly the morphology of the response for the case of a quasireversible electrode reaction of a dissolved redox couple. The electrode reaction attributed with the electrode kinetic parameter $\kappa=0.1$ appears quasireversible for $\Delta E=0.5$ $\mathrm{mV}$ (Figure 4A, panel (1)), whereas it is almost completely irreversible for $\Delta E=20 \mathrm{mV}$ (Figure 4A, panel (2)). On the other hand, the intensity of the response enhances significantly by increasing the step increment (compare panels 1 and 2 in Figure 4A). Obviously, the scan increment has a complex and profound effect to the voltammetric response of a quasireversible electrode reaction. Figure 4B summarizes in more detail the effect of the step potential increment to the typical kinetic regions of the electrode reaction considering the variation of the net peak current with the logarithm of the electrode kinetic parameter. The scan increment has a significant influence in the lower parts of the curves, which is associated to relatively slow and irreversible electrode processes, in agreement with the study of Jadresko et al. [66]. More specifically, the typical quasireversible kinetic region is expanded toward slower processes by decreasing the step increment (Figure 4B), implying that kinetic analysis of sluggish electrode reactions can be assessed by decreasing the step increment for a given frequency of the potential modulation. For $\log (\kappa) \geq 0$, the linearly increasing part of all curves merges into a single line, regardless of the step potential, indicating that in this kinetic region the electrochemical reversibility mainly depends on the frequency (cf. Figure 4B). Figure $4 \mathrm{C}$ also illustrates that the peak potential separation $\Delta E_{p}$ between the forward and backward components depends on both amplitude and the step potential increment. Obviously, lowering the step potential increment (curve 1 in Figure 4C) enables application of lower amplitude values (curve 3 in Figure 4C), which is highly advantageous in terms of precision and sensitivity of the method based on the amplitude variation [61]. 

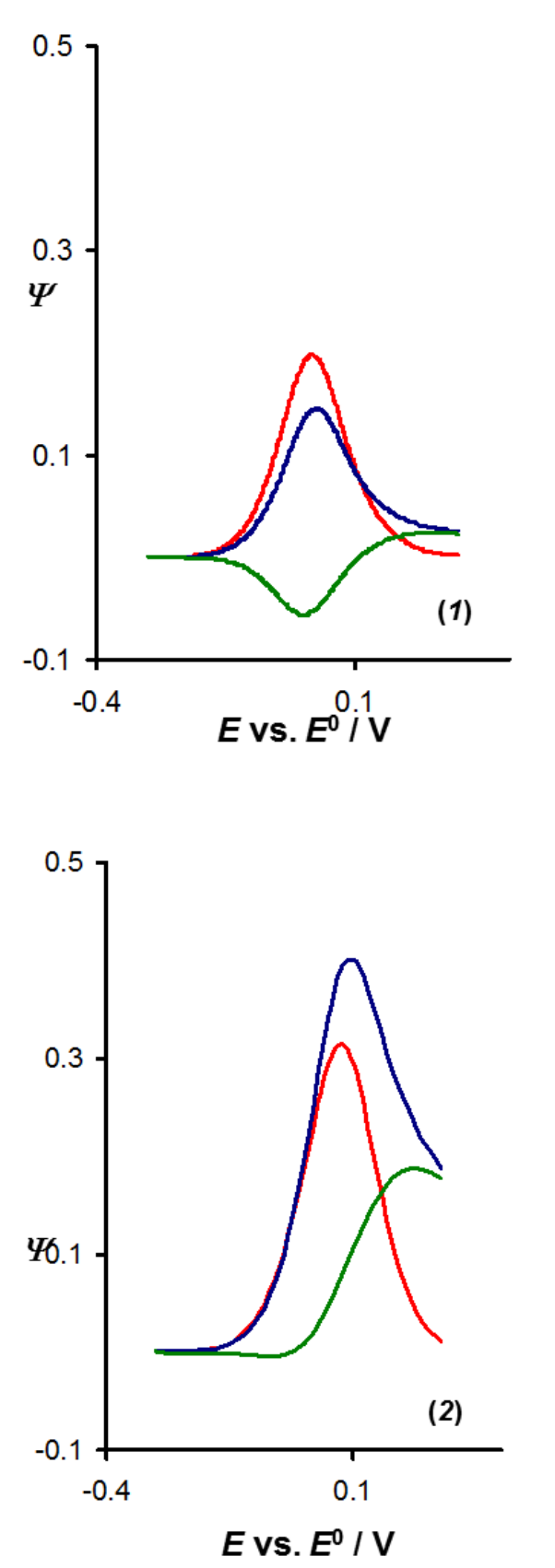

(A)

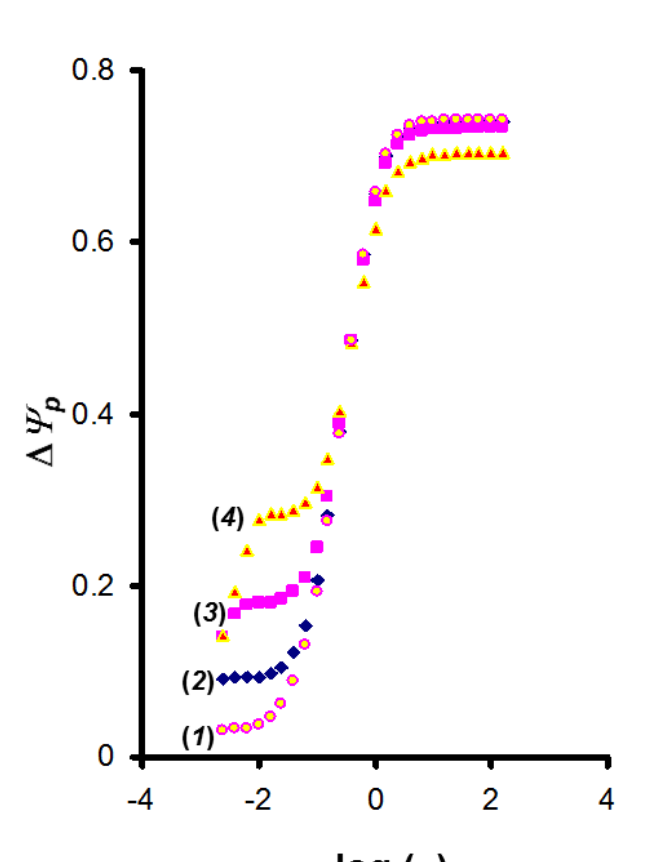

$\log (x)$

(B)

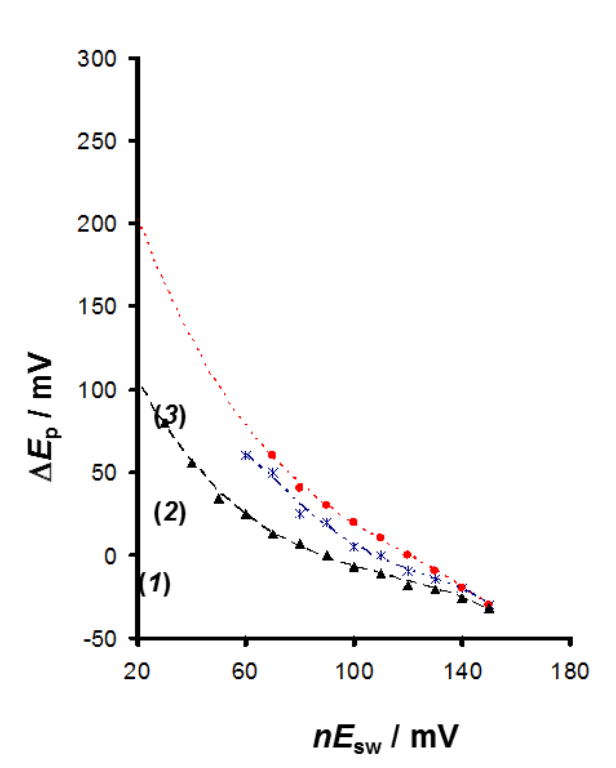

(C)

Figure 4. Quasireversible electrode reaction of a dissolved redox couple at a planar electrode. (A) The effect of the step potential increment on the morphology of the SW voltammograms for electrode kinetic parameter of $\kappa=0.1$, electron transfer coefficient $\alpha=0.5$ and stoichiometric number of electrons $n=1$. The amplitude of the modulation is $E_{\mathrm{sw}}=50 \mathrm{mV}$ and the step increment is $\Delta E=0.5(1)$ and $20 \mathrm{mV}$ (2). (B) The effect of the step potential increment on the quasireversible kinetic region for $\Delta E=0.1$ (1); 1 (2); 5 (3) and $20 \mathrm{mV}$ (4). (C) Peak potential separation as a function of the $\mathrm{SW}$ amplitude for the step potential increment of $\Delta E=1(1) ; 5$ (2) and $10 \mathrm{mV}$ (3).

To rationalize the effect of the scan increment let us note that the scan rate of the overall potential modulation can be significantly changed by altering the step potential increment for a given frequency $(v$ $=\Delta E f$ ). In turn, the scan rate determines the overall time of the voltammetric experiment, affecting the thickness of the diffusion layer and the rate of the diffusional mass transport for processes of a dissolved redox couple. For instance, at $f=5 \mathrm{~Hz}$, the scan rate changes from $v=0.5 \mathrm{mV} / \mathrm{s}$ to $100 \mathrm{mV} / \mathrm{s}$ for $\Delta E=0.1$ and $20 \mathrm{mV}$, respectively. It is three order of magnitude variation of the overall scan rate which has marked influence to the electrochemical reversibility of a given electrode reaction. Though 
the interplay of the frequency and scan rate is very complex, it is highly advised to inspect in detail the effect of the step increment and to develop methodology for kinetic estimation of slow electrode processes. A general recommendation would be to apply as small as possible step potential increment when sluggish electrode mechanisms are subject of the study.

\section{In-depth analysis of chronoamperometric} features of electrode processes - multisampling procedure in SWV

Understanding SWV as a repetitive doublestep chronoamperometric technique, a novel methodology has been recently proposed for advanced analysis based on the multisampling current procedure [67]. The basic idea is graphically illustrated in Figure 5, showing a single potential cycle in SWV (Figure 5A) where the current is sampled at several time intervals at the last portion of the pulse. Instead of single current measurement, the multisampling current procedure enables construction of a series of so called multi-sampled $S W$ voltammograms, which reflect the chronoamperometric behaviour of the electrode reaction. Proposed procedure is useful when the experiment is conducted at a low frequency, i.e. long duration of the potential pulses, allowing to sample the current at the last portion of each pulse without sacrificing the large ratio of the faradaic to the charging current $[1,11]$

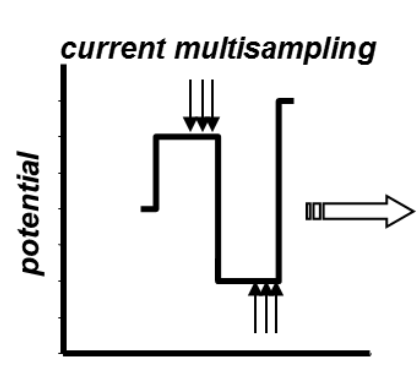

time
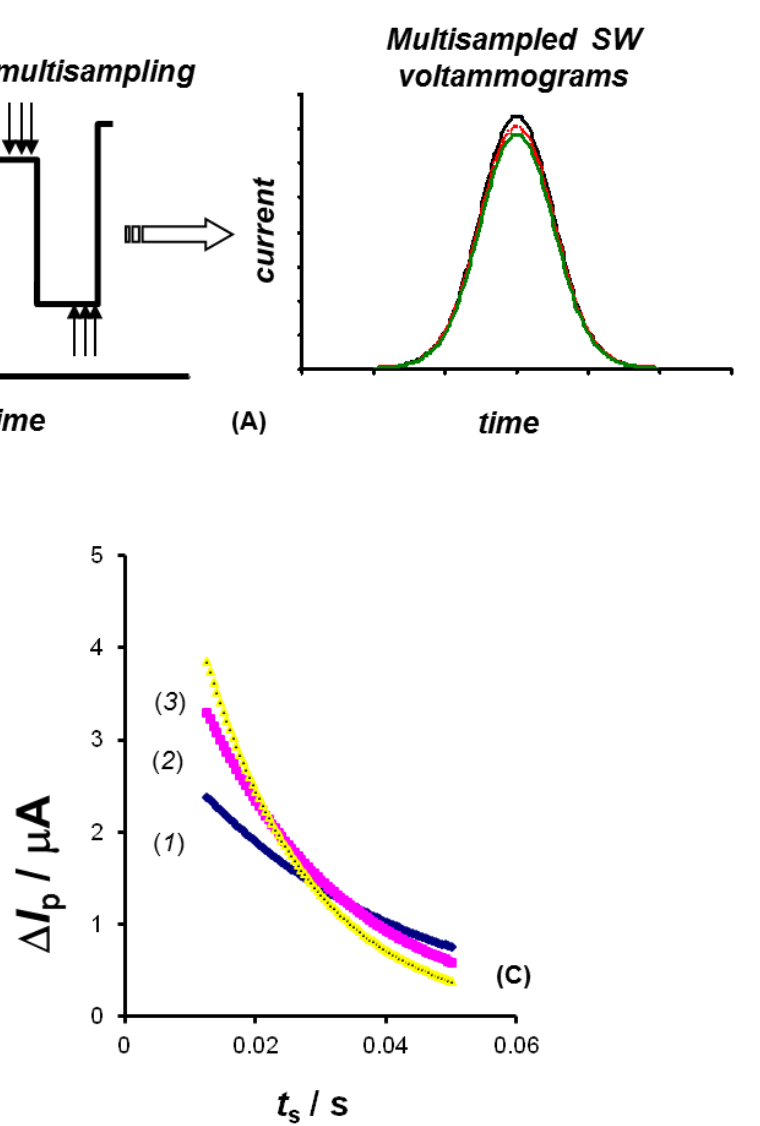
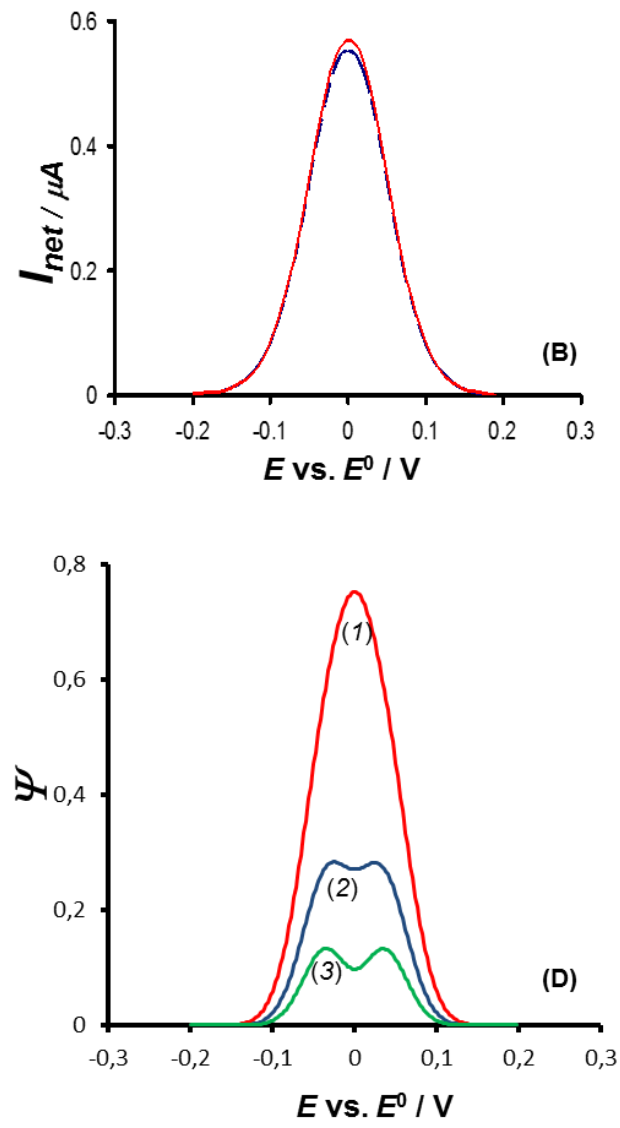

Figure 5. (A) Multisampling current procedure in the course of a single potential cycle in SWV and corresponding multisampled net SW voltammograms. (B) Comparison of net voltammetric components of a reversible electrode reaction of a dissolved redox couple simulated at $f=10 \mathrm{~Hz}\left(t_{\mathrm{p}}=50 \mathrm{~ms}\right)$ by sampling the current at $t_{\mathrm{s}}=40 \mathrm{~ms}$ (red line) with the conventional voltammogram (blue dashed line) simulated for $f=12.5 \mathrm{~Hz}\left(t_{\mathrm{p}}=t_{\mathrm{s}}=40 \mathrm{~ms}\right)$. (C) Quasireversible electrode reaction of a surface confined redox couple. The dependence of the real net peak current of multisampled SW voltammograms on the sampling time for the formal rate constant of $k_{\text {sur }} / \mathrm{s}^{-1}=10(1) ; 15$ (2), and 25 (3). Electron transfer coefficient is $\alpha=0.5$, stoichiometric number of electrons $n=1$, frequency $f=10 \mathrm{~Hz}$, amplitude $E_{s w}=50 \mathrm{mV}$, and scan increment is $\Delta E=2 \mathrm{mV}$. (D) Evolution of the multisampled theoretical net voltammograms of surface confined electrode reaction for a sampling time of $t_{\mathrm{s}}=30($ (1);40 (2) and $50 \mathrm{~ms}$ (3). The formal rate constant is $k_{s u r}=35 \mathrm{~s}^{-1}$. The other conditions are identical as for the panel (C). 
Figure 5B illustrates the difference between multisampled and conventional SW voltammograms for a reversible electrode reaction of a solution resident redox couple. The red line corresponds to the net voltammogram simulated at $f=10 \mathrm{~Hz}$ (duration of a single pulse $t_{p}=50 \mathrm{~ms}$ ) but sampling the current at $t_{s}=40 \mathrm{~ms}$, whereas the blue dashed line refers to the conventional voltammogram simulated at $f=12.5 \mathrm{~Hz}\left(t_{p}=t_{s}=40 \mathrm{~ms}\right)$. Even though in the two cases the current is sampled at equal time $(40 \mathrm{~ms})$, the outcome of the two assumed experiments is not identical, revealing the difference in the multisampling and conventional SWV.

The main advantage of multisampling SWV originates from the fact that in a single experiment one can construct a series of SW voltammograms, the analysis of which might enable full characterisation of the reaction [67]. A theoretical example of such analysis is presented in Figure 5C showing the variation of the net peak current of the multisampled net voltammograms as a function of the sampling time for a surface confined electrode reaction. The net peak current variation with sampling time is sensitive to the electrode kinetics enabling estimation of the formal rate constant. Moreover, the evolution of the net voltammogram from a single peak to the split net peak, typical for a surface confined electrode reaction, can be observed by analyzing multisampled voltammograms (Figure 5D). Let us recall that the peak splitting in conventional SWV is achievable either by increasing the SW amplitude or decreasing the frequency of the potential modulation [62]. Obviously, in multisampling SWV, the phenomenon can be observed conducting a single votammetric experiment only, which seems to be a unique feature of the proposed methodology. The proposed method is promising for an advanced analysis of electrode processes, as initially experimentally verified with the reactions of $\mathrm{Eu}^{3+}$ and azobenzene [67]. It is however worth mentioning that the full implementation of the method depends yet on the modification of current sampling protocol in the modern digital instrumentation.

\section{Square-wave voltammetry in a cyclic fashion mode}

It is commonly claimed that SWV unifies the advantages of pulse voltammetric techniques (with respect to the high ratio of the faradaic to the charging current, i.e., high analytical sensitivity), and cyclic voltammetry (with respect to the ability to study electrode mechanism). Nevertheless, in conventional SWV mechanistic features are accessible only for relatively fast electrode processes attributed with high electrochemical reversibility under given ex- perimental conditions. For slow processes, as discussed in the previous section, a series of obstacles need to be overcome. A possible solution could be found in coupling the conventional SWV with cyclic voltammetry to yield the potential modulation presented in Figure 6A. The theoretical basis of this highly promising technique are found in the works of Chen [68], Bottomley [69-71], Molina [72], as well as in a series of studies in which SWV was applied in a reverse mode [73-76].

Figure 6B shows a typical theoretical response of the cyclic square-wave voltammetry of a slow, quasireversible electrode reaction of a dissolved redox couple. The response is rich with electrochemical data, consisting of six voltammetric curves, attributed to the direct and reversal SW potential scan. For the sake of simplicity, the cyclic square-wave voltammogram might feature the net components of the direct and reversal scan only. Analyzing the same electrode reaction shown in Fig. 6B with conventional SWV yields an irreversible voltammetric response with barely developed backward component. On the contrary, under conditions of cyclic square-wave voltammetry the processes appears as quasireversible one considering the net components of the response, providing an insight into the mechanistic and kinetic aspects of the electrode reaction.

Figure 6C shows a typical response of a $\mathbf{E C}_{\text {rev }}$ electrode mechanism, where the quasireversible electrode reaction of a dissolved redox couple $(\mathbf{E})$ is coupled with a follow-up reversible homogeneous chemical reaction $\left(\mathbf{C}_{\text {rev }}\right)$, attributed with a equilibrium rate constant $\log (K)=10$ and different kinetics of the chemical step [1]. As the kinetics of the chemical reaction increases, the net component of the reversal SW voltammetric scan diminishes, in analogy to the cyclic voltammetric features. Recall that the dimensionless chemical kinetic parameter is defined as $\varepsilon=\frac{k}{f} ; k=k_{f}+k_{b}$ is cumulative rate constant where $k_{f}$ and $k_{b}$ are rate constants of the direct and reverse chemical reaction of the chemical step [1]. The evolution of the response presented on Figure $6 \mathrm{C}$ is similar to the conventional cyclic voltammetry, the difference being in the advanced sensitivity and high quality of the electrochemical data under conditions of cyclic square-wave voltammetry.

In conclusion, it has to be stressed that there is a necessity for the analysis of a variety of electrode mechanisms under conditions of cyclic squarewave voltammetry in order to establish qualitative diagnostic criteria as well as to develop methods for determination of thermodynamic and kinetic parameters of electrode reactions. 

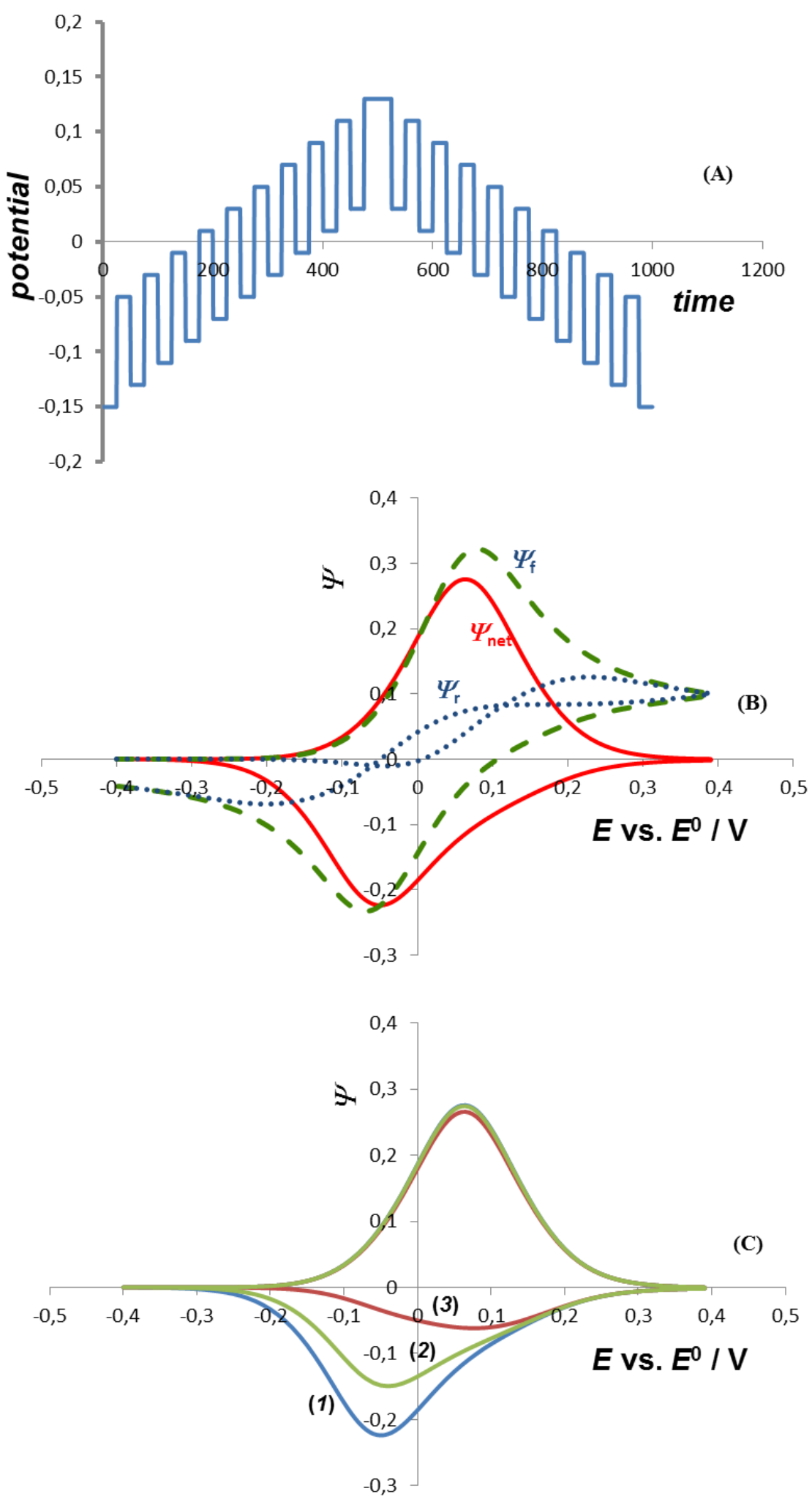

Figure 6. (A) Potential modulation in cyclic square-wave voltammetry. (B) Typical voltammetric response of a quasireversible electrode reaction of a solution resident redox couple showing, forward, reverse and net component. Simulations are conducted for electrode kinetic parameter $\kappa=1$, electron transfer coefficient $\alpha=0.5$, stoichiometric number of electrons $n=1$, amplitude $E_{\mathrm{sw}}=50 \mathrm{mV}$, and scan increment $\Delta E=10 \mathrm{mV}$. (C) Typical response of an $\mathbf{E C}_{\text {rev }}$ mechanism for the chemical kinetic parameter of: $\log (\varepsilon)=-5(1) ;-2(2)$ and $-1(3)$. The equilibrium constant of the chemical step is $\log (K)=10$ and the electrode kinetic parameter is 0.1 . The other conditions are identical as for panel (B). 
Simplified form of square-wave voltammetry square-wave chronoamperometry

Square-wave chronoamperometry is a simplified form of conventional square-wave voltammetry developed for the purpose of simplification and broadening the scope of the technique [77]. The theoretical base of this renewed idea is found in the early works of Smit and Wijnen [78-80], in the methodology known as cyclic potential-step method. Square-wave chronoamperometry is a pulseform chronoamperometric experiment, the excitation signal being obtained by combining a constant potential (mid-potential, $E_{\text {mid }}$ ) with a short-duration, small potential pulses, as depicted in Figure 7A. Indeed, the proposed experiment is a repetitive double-step chronoamperometric experiment conducted with small potential pulses. The main tool in hand for electrokinetic purposes is again the frequency $(f)$, the height of potential pulses $\left(E_{s w}\right.$, i.e. SW amplitude), as well as the mid potential $\left(E_{m i d}\right)$. Current sampling and presentation of chronoamperometric data is analogous to SWV, consisting of forward,
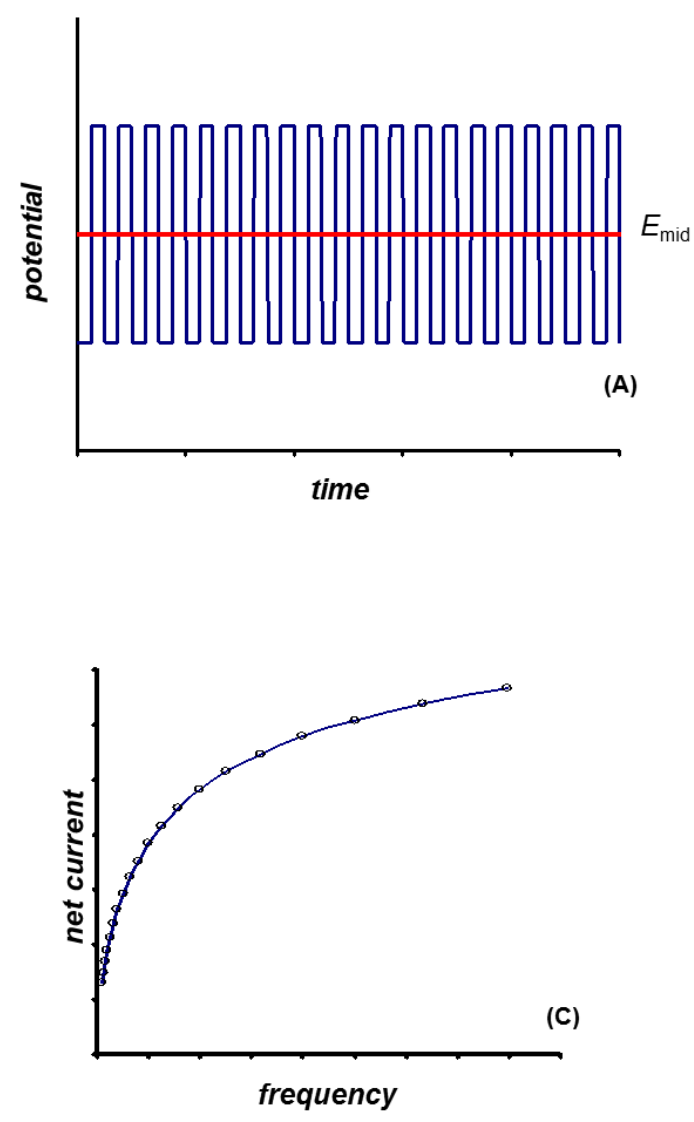

reverse, and net (differential) chronoamperometric curve (Figure 7B). Additionally, for electrokinetic purposes, the typical way of presenting the data is in the form of a "spectrum" of net currents as a function of the frequency (Figure 7C), which is the reason to coin an alternative name of the technique electrochemical faradaic spectroscopy.

The first, and the most striking feature of the response is that the net chronoamperometric component does not depend on time of the experiment, as illustrated in Figure 7D, referring to the reversible electrode reaction of a solution resident redox couple. Such chronoamperometric behaviour is opposite to the conventional chronoamperometry (cf. Figure 7D), where the current decays with time $\left(\sim \frac{1}{\sqrt{t}}\right)$, as typical for diffusion controlled processes at macroscopic electrodes. Thus, the response under conditions of electrochemical faradaic spectroscopy at a macroscopic electrode resembles the steady state response in conventional chronoamperometry at microelectrodes governed by a spherical diffusion mass transport.
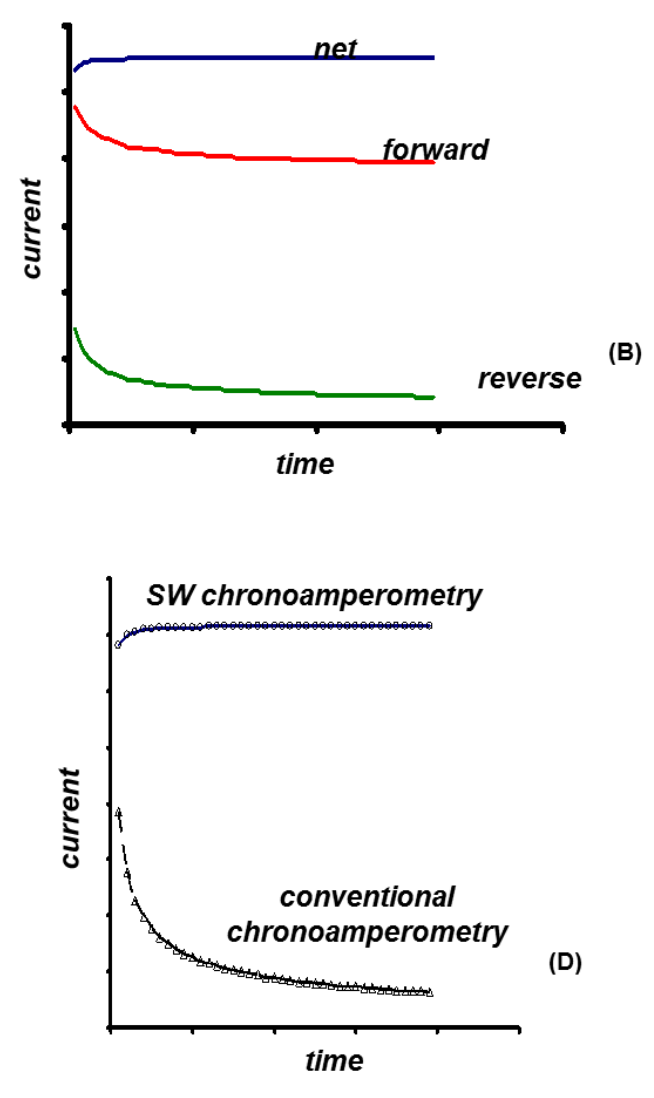

Figure 7. Electrochemical faradaic spectroscopy (EFS): (A) A scheme of the excitation signal; (B) typical response of EFS in a form of square-wave chronoamperogram; (C) typical response of EFS in a form of a spectrum of net currents of different frequencies. (D) Comparison of the net response in EFS and conventional chronoamperometry. 
Figure 8 illustrates that the frequency spectrum is sensitive to both electrode kinetics and mechanism, exemplified with the quasireversible electrode reaction of a solution resident redox couple (curve 1), surface confined electrode reaction (curve 2), and $\mathbf{E}_{\text {rev }} \mathbf{C}^{\prime}$ regenerative catalytic mechanism of a reversible electrode reaction of a dissolved redox couple (curve 3) [1]. The theoretical analysis is conducted at the mid potential identical to the corresponding formal potentials of each electrode mechanism, with 20 potential cycles (i.e., in total 40 potential pulses at amplitude of $E_{s w}=20 \mathrm{mV}$ ). The parabolic spectrum of the surface confined electrode reaction is a consequence of the specific chronoamperometric features related to the phenomenon known as quasireversible maximum $[1,11]$.
Generally, the proposed simple technique unifies the advantages of both conventional squarewave voltammetry and chronoamperometry. With respect to the kinetics of the electrode reaction of a dissolved redox couple the technique appears to be even more sensitive than SWV and conventional chronoamperometry [77]. Moreover, in comparison to SWV even faster electrode reactions can be studied by adjusting the mid-potential $\left(E_{\text {mid }}\right)$ at values $E_{\text {mid }}<E^{0^{\prime}}$. Finally, it has to be mentioned, similar to the case of multisampling current procedure (section In-depth analysis of chronoamperometric features...), the application of the new methodology depends on the implementation of the technique in the modern instrumentation. Moreover, the complete theoretical development considering a variety of electrode processes should follow.

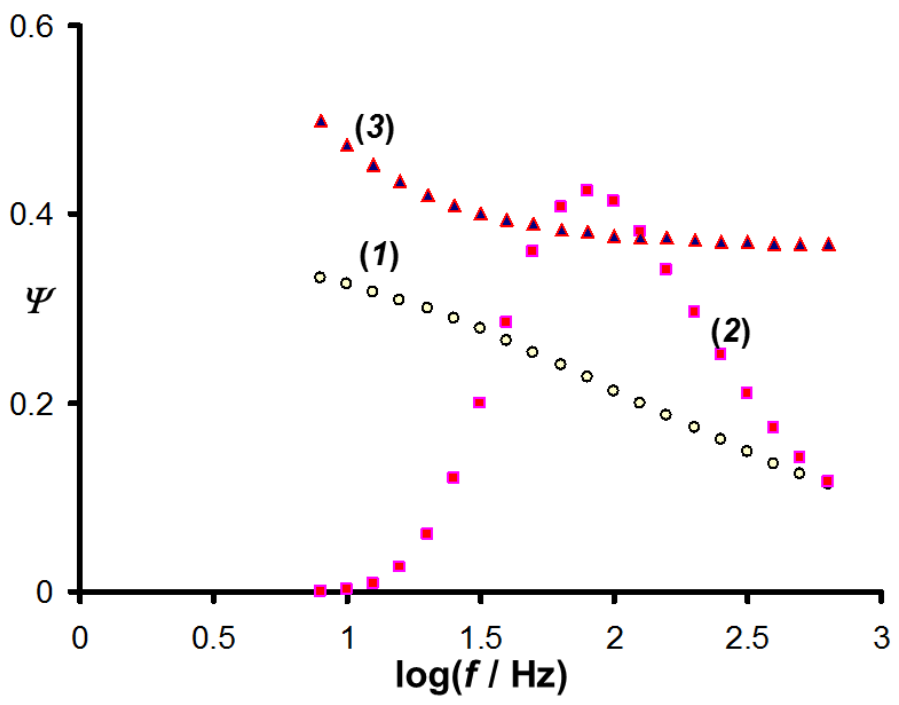

Figure 8. Typical frequency spectrum in electrochemical faradaic spectroscopy for (1) a quasireversible electrode reaction of a solution resident redox couple with a formal rate constant $k_{s}=0.01 \mathrm{~cm} \mathrm{~s}^{-1} ;(2)$ quasireversible surface confined electrode reaction with a formal rate constant $k_{\text {sur }}=100 \mathrm{~s}^{-1}$; and (3) reversible catalytic electrode mechanism with the catalytic rate constant $k_{c}=10 \mathrm{~s}^{-1}$. The other conditions of the simulations are: stoichiometric number of electrons $n=1$, electron transfer coefficient $\alpha=0.5$, amplitude $E_{s w}=20 \mathrm{mV}$, and number of potential cycles $p=20$. The dimensionless currents correspond to the $19^{\text {th }}$ potential cycle measured for different frequencies.

\section{TOWARDS ENHANCED SENSITIVITY OF SQUARE-WAVE VOLTAMMETRY}

Finally, in a quest for improved analytical performances of SWV two new ideas are presented here for the first time. The full elaboration will be given in subsequent separate publications. The first one is an attempt to increase the sensitivity of SWV by simple processing of conventional net voltammograms, leading to the methodology provisionally termed as cumulative square-wave voltammetry. In cumulative voltammetry the current at a given potential $\left(\Psi_{\text {cum }}\right)$ is calculated as a sum of all previous current values of the conventional SWV ( $\Psi$ ), i.e., $\Psi_{\text {cum }}=\sum_{j} \Psi_{j}$. The result of such operation, which could be regarded as primitive integration, is presented in Figure 9, comparing conventional (left ordinate) with the new, cumulative net voltammogram (right ordinate). The cumulative voltammogram is a sigmoid curve with a limiting current $\left(\Psi_{\text {lim }}\right)$ that is an order of magnitude higher than the net peak-current of the conventional SW voltammogram $\left(\Delta \Psi_{p}\right)$ (compare the range of values of the two ordinates). For the conditions of Figure 9, the ratio is $\Psi_{\text {lim }} / \Delta \Psi_{p}=26.5$. In order to illustrate the prom- 
ising potential of the proposed methodology toward an increased analytical sensitivity, the inset of Figure 9 compares theoretically constructed calibration lines of conventional and cumulative SWV. While the improvement in the sensitivity of the technique is obvious, it should be noted that the limit of detection of two techniques is expected to be identical, as they rely on the same set of electrochemical data.

The first, preliminary experimental verification of the proposed methodology has been done with the experiments with $\mathrm{H}_{2} \mathrm{O}_{2}$ measurement at macroscopic Pt electrode, where the slope of the calibration line increased from 21.26 to 693.07 A $\mathrm{mmol}^{-1} 1$ for conventional and cumulative SWV, respectively (data not shown).

From the mechanistic point of view it can be mentioned that the half-wave of the cumulative voltammogram is identical to the net peak potential. It can be also shown that the rising part of the cumulative voltammogram is a linear function of the potential. The slope of the linear part of the cumulative voltammogram and the half-wave potential are sensitive to the electrochemical reversibility, thus enabling further processing and estimation of the kinetic parameters.

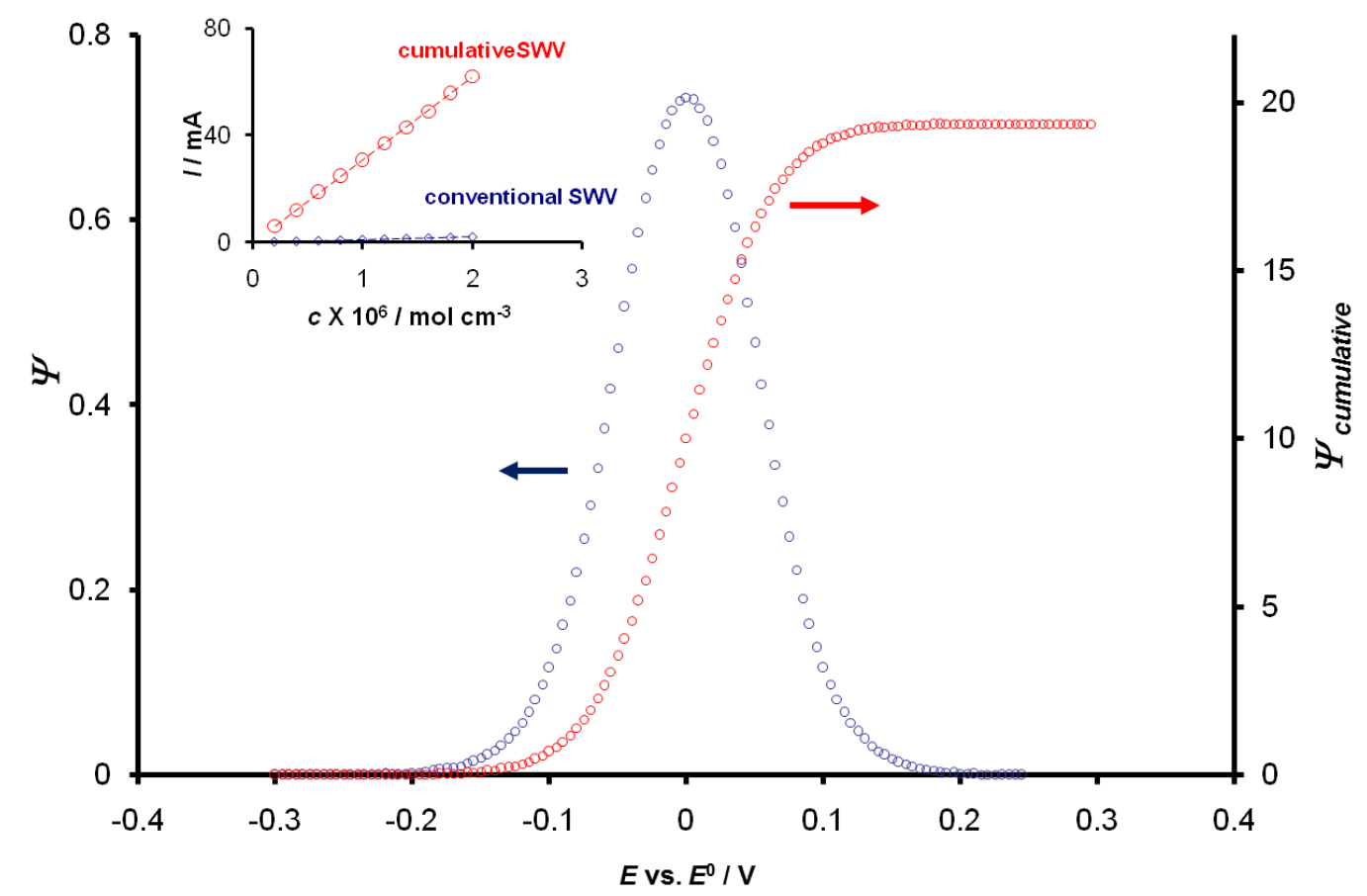

Figure 9. Cumulative square-wave voltammetry of a quasireversible electrode reaction at a planar electrode of a solution resident redox couple. Comparison of the cumulative (right ordinate) with the conventional SW voltammogram (left ordinate). Conditions of the simulations are: electrode kinetic parameter $\log (\kappa)=1.8$, electron transfer coefficient $\alpha=0.5$, stoichiometric number of electrons $n=1$, amplitude $E_{\mathrm{sw}}=50 \mathrm{mV}$, and scan increment $\Delta E=5 \mathrm{mV}$. The inset shows the theoretical calibration curves for the cumulative and conventional SWV. Conditions of the simulations are: formal rate constant $k_{s}=10^{-3} \mathrm{~cm} \mathrm{~s}^{-1}$, electrode surface area $A=0.01 \mathrm{~cm}^{2}$; common diffusion coefficient $D=1 \times 10^{-6} \mathrm{~cm}^{2} \mathrm{~s}^{-1}$ and frequency $f=10 \mathrm{~Hz}$. The other conditions are identical as for the main graph.

Besides sensitivity, the improvement of the limit of detection of SWV is a highly challenging issue in the overall methodological development of the technique. In the family of pulse voltammetric techniques SWV and differential pulse voltammetry (DPV) [4] compete for dominance in electroanalytical chemistry in general. While SWV seems to be superior when electrode mechanisms and kinetics are the subject of the study, analytical performances of the two techniques are quite comparable. In $\mathrm{SWV}$, the frequency is the main time parameter $(f=$ $1 / \tau=1 / 2 t_{p}$ ) (Figure 10A), while in DPV both dura- tion of the step $\left(t_{s}\right)$ and the pulse $\left(t_{p}\right)$ can be deliberately altered (Figure 10B). In many cases, the right choice of the ratio $t_{s} / t_{p}$ provides superior analytical performances of DPV. In order to unify the advantages of the two techniques a hybrid potential modulation is proposed, as depicted in Figure 10C. The later can be understood as a modified form of DPV, where the single pulse is replaced with two, equal, oppositely oriented pulses. Clearly, the underlying idea is to keep the ability of the hybrid technique to provide mechanistic information as SWV does. On the other hand, the hybrid potential 
form can be commented from the perspective of SWV noting that a potential step $\left(t_{s}\right)$ is inserted between potential cycles; commonly $t_{s}>t_{p}$. Obviously, the tendency is to enable longer relaxation of the system at a given potential step of the staircase potential modulation, in order to increase the ratio between the faradaic and charging current, as effectively achieved in DPV [4].

The current sampling of the hybrid technique can be done at three points, i.e., at the end of the step $\left(I_{s}\right)$, as well as at the end of each potential pulse ( $I_{f}$ and $I_{r}$ ) (cf. Figure 10C). Two differential current components can be defined as $I_{d i f, f}=I_{f}-I_{s}$, and ${ }_{d i f, r}$ $=I_{r}-I_{s}$. In addition, the net component can be calculated as $I_{n e t}=I_{d i f, f}-I_{d i f, r}$. The same net component is obtained through $I_{f}$ and $I_{r}$ as $I_{n e t}=I_{f}-I_{r}$.
As depicted in Figure 11 the evolution of the differential current components ( $I_{d i f, f,} I_{d i f, r}$, Figure 11A) is not identical with the forward and reverse current components $\left(I_{f}, I_{r}\right.$, Figure 11A), though the net component is identical in both cases. Interrelation between differential current components implies a quasireversible electrode process (cf. Figure 11A), whereas the forward and reverse currents are typical for the irreversible electrode reaction (cf. Figure 11B). The overall characteristics of the response are expected to depend strongly on the ratio $t_{p} / t_{s}$, in both mechanistic contexts, as well as in terms of the analytical performances of the technique. An in-depth theoretical analysis is in progress, which will be the subject of following communications.
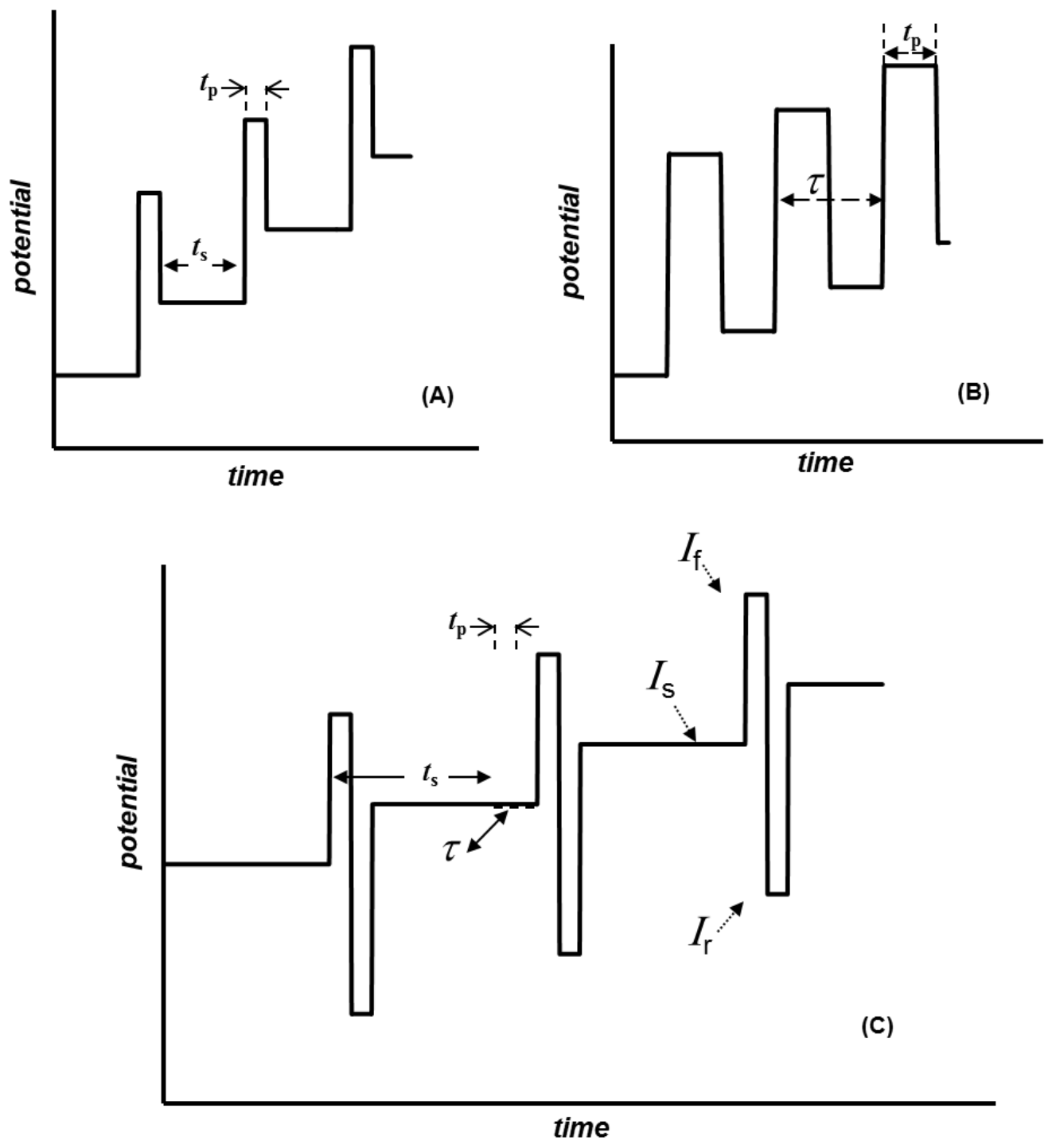

Figure 10. (A) Potential modulation in differential pulse voltammetry; (B) square-wave voltammetry; (C) hybrid differential-pulse square-wave voltammetry, showing typical time intervals and current sampling points in the new hybrid technique 

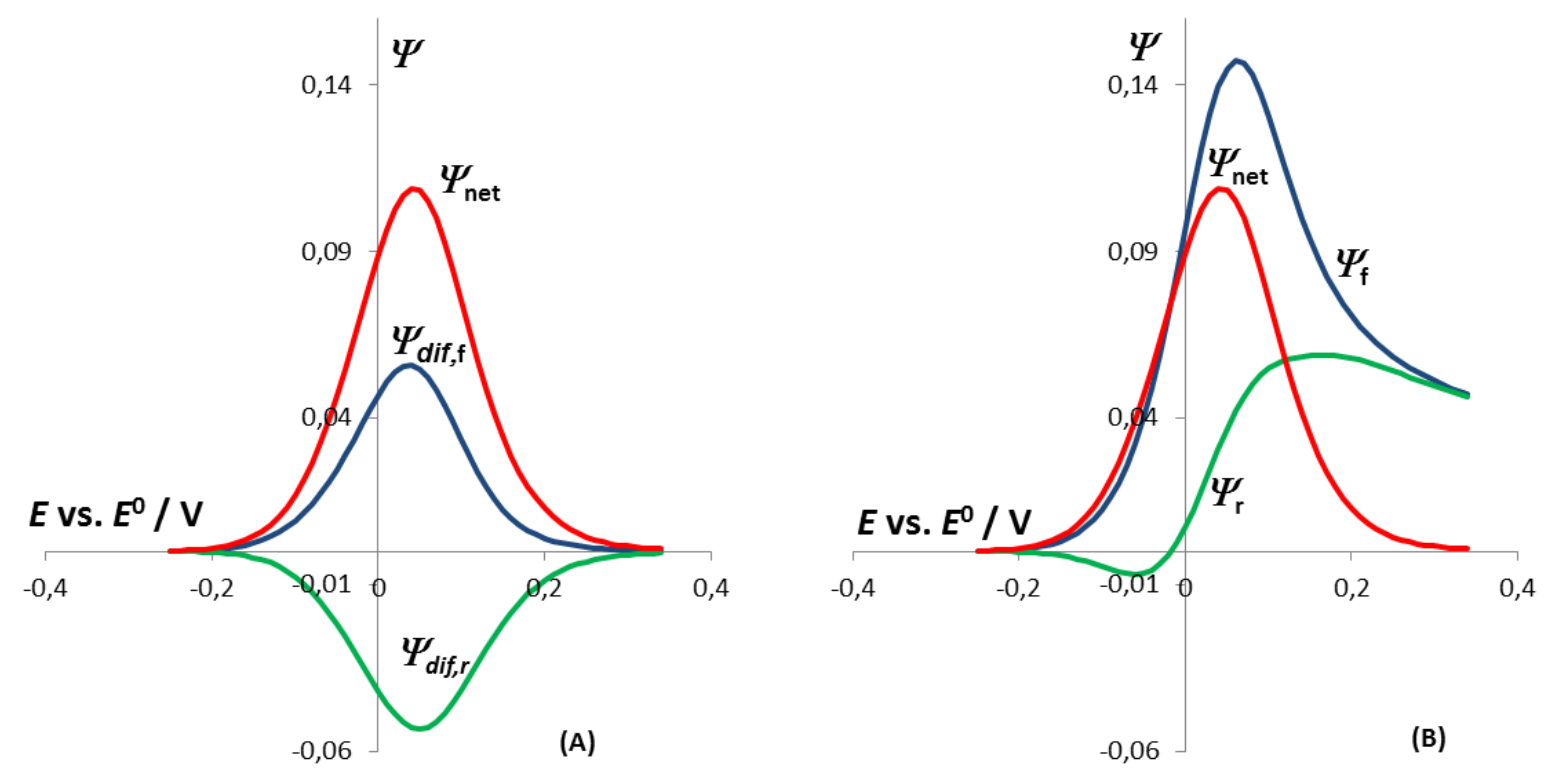

Figure 11. Quasireversible electrode reaction of a dissolved redox couple at a planar electrode. Typical theoretical response under conditions of hybrid differential pulse-square voltammetry showing: (A) differential ( $\left.\Psi_{\text {diff, }}, \Psi_{\text {dif, }, \text { r }}\right)$ current components and $(\mathbf{B})$ forward $\left(\Psi_{\mathrm{f}}\right)$ and reverse $\left(\Psi_{\mathrm{r}}\right)$ current components. In both cases, the net component ( $\left.\Psi_{\text {net }}\right)$ is also given. The simulation conditions are: electrode kinetic parameter $\kappa=0.1$, electron transfer coefficient $\alpha=0.5$ and stoichiometric number of electrons $n=1$. The ratio between critical time parameters is $t_{s} / t_{p}=6$, the amplitude of the modulation is $E_{\mathrm{sw}}=25 \mathrm{mV}$ and the scan increment is $\Delta E=10 \mathrm{mV}$.

\section{REFERENCES}

[1] V. Mirčeski, Š. Komorsky-Lovrić, M. Lovrić, Square-wave voltammetry: Theory and application, F. Scholz (Ed.), Springer Verlag, Heidelberg, 2007.

[2] G. N. Eccles, Recent advances in pulse, cyclic and square-wave voltammetric analysis, Crit. Rev. Anal. Chem. 22 (1991), pp. 345-380.

[3] D. de Souza, S. A. S. Machado, L. A. Avaca, Square-wave voltammetry. Part I: Theoretical aspects, Quim. Nova, 26 (2003), pp. 81-89.

[4] Á. Molina, J. González, Pulse Voltammetry in Physical Electrochemistry and Electroanalysis. Theory and Applications, Series: Monographs in Electrochemistry, Fritz Scholz (Ed.), Springer, Berlin, 2016.

[5] M. Kalousek, Processes at the dropping electrode with a discontinuously changing potential, Collect. Czech. Chem. Commun., 13 (1948), pp. 105-115.

[6] G. C. Barker, A. W. Gardner, Square-wave polarography, Analyst, 117 (1992), pp. 1811-1828.

[7] G. C. Barker, I. L. Jenkins, Square-wave polarography, Analyst, 77 (1952), pp. 685-696.

[8] G. C. Barker, Square-wave polarography and some related techniques, Anal. Chim. Acta., 18 (1958), pp. 118-131.

[9] J. H. Christie, J. A. Turner, R. A. Osteryoung, Square wave voltammetry at the dropping mercury electrode: Theory, Anal. Chem., 49 (1977), pp. 1899-1903.
[10] J. Osteryoung, J. J. O'Dea, Square-wave voltammetry, in: Electroanalytical chemistry, A. J. Bard (Ed.), Marcel Dekker, New York, 1986, 14, pp. 209-308.

[11] M. Lovrić, Square-wave voltammetry, in: Electroanalytical Methods, F. Scholz (Ed.) Springer, Berlin, 2002.

[12] J. Gonzalez, A. Molina, F. Martinez Ortiz, E. Laborda, Characterization of the electrocatalytic response of monolayer-modified electrodes with square-wave voltammetry, J. Phys. Chem. C, 116, 20 (2012), pp. 11206-11215.

[13] E. Laborda, A. Molina, Q. Li, C. BatchelorMcAuley, R. G. Compton, Square wave voltammetry at disc microelectrodes for characterization of two electron redox processes, Phys. Chem. Chem. Phys., 14 (2012), pp. 8319-8327.

[14] A. Molina, J. Gonzalez, E. Laborda, Y. Wang, R. G. Compton, Analytical theory of the catalytic mechanism in square wave voltammetry at disc electrodes, Phys. Chem. Chem. Phys., 13 (2011), 16748-16755.

[15] Y. Wang, E. Laborda, M. C. Henstridge, F. MartinezOrtiz, A. Molina, R. G. Compton, The use of differential pulse voltammetries to discriminate between the Butler-Volmer and the simple Marcus-Hush models for heterogeneous electron transfer: The electroreduction of europium (III) in aqueous solution, $J$. Electroanal. Chem., 668 (2012), pp. 7-12.

[16] M. C. Henstridge, E. Laborda, R. G. Compton, Asymmetric Marcus-Hush model of electron trans- 
fer kinetics: Application to the voltammetry of surface-bound redox systems, J. Electroanal. Chem., 674 (2012), pp. 90-96.

[17] R. Gulaboski, L. Mihajlov, Catalytic mechanism in successive two-step protein-film voltammetryTheoretical study in square-wave voltammetry, $B i$ ophys. Chem., 155 (2011), pp. 1-9.

[18] R. Gulaboski, M. Lovrić, V. Mirčeski, I. Bogeski, M. Hoth, A new rapid and simple method to determine the kinetics of electrode reactions of biologically relevant compounds from the half-peak width of the square-wave voltammograms, Biophys. Chem., 138 (2008), pp. 130-137.

[19] M. Zhou, S. Gan, L. Zhong, B. Su, L. Niu, Ion transfer voltammetry by a simple two polarized interfaces setup, Anal. Chem., 82 (2010), pp. 78577860 .

[20] D. Krulic, N. Fatouros, Peak heights and peak widths at half-height in square wave voltammetry without and with ohmic potential drop for reversible and irreversible systems, J. Electroanal. Chem., 652 (2011), pp. 26-31.

[21] D. Krulic, N. Fatouros, Square wave voltammetry of concentrated analytes in fully supported solutions $-\mathrm{Cd}(\mathrm{II}) / \mathrm{Cd}(\mathrm{Hg})$ couple in $\mathrm{NaNO}_{3}$ medium. $J$. Electroanal. Chem., 655 (2011), pp. 116-119.

[22] J. Zhang, S. X. Guo, A. M. Bond, J. M. Honeychurch, K. B. Oldham, Novel kinetic and background current selectivity in the even harmonic components of Fourier transformed square-wave voltammograms of surface-confined azurin, $J$. Phys. Chem. B, 109 (2005), pp. 8935-8947.

[23] B. D. Fleming, N. L. Barlow, J. Zhang, A. M. Bond, F. A. Armstrong, Application of power spectra patterns in Fourier transform square wave voltammetry to evaluate electrode kinetics of surfaceconfined proteins, Anal. Chem., 78 (2006), pp. 2948-2956.

[24] X. Huang, L. Wang, S. Liao, Method of evaluation of electron transfer kinetics of a surface-confined redox system by means of Fourier transformed square wave voltammetry, Anal. Chem., 80 (2008), pp. 5666-5670.

[25] G. W. C. Milner, L. J. Slee, Analytical applications of the Barker square-wave polarograph. Part III. Orthophosphoric acid as a solvent and base electrolyte in direct inorganic polarographic analysis, Analyst, 82 (1957), pp. 139-151.

[26] W. F. Kinard, R. H. Philip, R. C. Propst, Analytical applications of Kalousek polarography, Anal. Chem., 39, 13 (1967), pp. 1556-1562.

[27] G. Geerinck, H. Hilderson, C. Vanttulle, F. Verbeck, Square wave polarography, J. Electroanal. Chem., 5 (1963), pp. 48-56.

[28] R. E. Hamm, Square-Wave Polarograph, Anal. Chem., 30, 3 (1958), pp. 351-354.

[29] B. Y. Kaplan, T. N. Sevastyanova, Advantages of debalance-method in substractive square-wave polarography, Zh. Anal. Khim., 26 (1971), pp. 1054.
[30] H. Blutstein, A. M. Bond, Fast sweep differential pulse voltammetry at a dropping mercury electrode, Anal. Chem., 48, 2 (1976), pp. 248-252.

[31] M. Kopanica, V. Stara, Fast-scan differential pulse polarography in pre-enriched solution, J. Electroanal. Chem. 127 (1981), pp. 255-261.

[32] P. W. Alexander, V. Akapongkul, Differential pulse voltammetry with fast pulse repetition times in a flow-injection system with a copper-amalgam electrode, Anal. Chim. Acta, 166 (1984), pp. 119-127.

[33] L. Ramaley, W.T. Tan, Single drop square wave polarography, Can. J. Chem. 59, 24 (1981), pp. 3326-3333.

[34] J. Y Hwang, Y. Y. Wang, C.C. Wan, A Theoretical analysis of single drop square-wave polarography, J. Chin. Chem. Soc., 33 (1986), pp. 302-307.

[35] V. Mirčeski, R. Gulaboski, M. Lovrić, I. Bogeski, R. Kappl, M. Hoth, Square-wave voltammetry: a review on the recent progress, Electroanalysis, 25, 11 (2013), pp. $2411-2422$.

[36] V. Mirčeski, R. Gulaboski, Recent Achievements in Square-Wave Voltammetry - A Review, Macedonian Journal of Chemistry and Chemical Engineering, 33 (2014), pp. 1-12.

[37] M. Geissler, C. Kuhnhardt, Square-wavePolarographie, VEB Deutscher Verlagfur Grundstoffindustrie, Leipzig, 1970.

[38] L. Ramaley, M. S. Krause Jr., Theory of square wave voltammetry, Anal. Chem., 41, 11 (1969), pp. 1362-1365.

[39] M. S. Krause Jr., L. Ramaley, Analytical application of square wave voltammetry, Anal. Chem., 41, 11 (1969), pp. 1365-1369.

[40] E. Laborda, J. González, Á. Molina, Recent advances on the theory of pulse techniques: A mini review, Electrochemistry Communications, $\mathbf{4 3}$ (2014), pp. 25-30.

[41] M. Lovrić, Simulation of square wave voltammetry of three electrode reactions coupled by two reversible chemical reactions, J. Electrochem. Sci. Eng., 7, 3 (2017) pp. 119-129.

[42] M. Lovrić, Š. Komorsky-Lovrić, Theory of square wave voltammetry of three step electrode reaction, Journal of Electroanalytical Chemistry, $\mathbf{7 3 5}$ (2014), pp. 90-94

[43] Š. Komorsky-Lovrić, D. Jadreško, M. Lovrić, Theory of square wave voltammetry of amalgam forming ions at spherical electrodes, Electrochimica Acta, 130 (2014), pp. 286-289.

[44] M. Lovrić, D. Jadreško, Š. Komorsky-Lovrić, Theory of square-wave voltammetry of electrode reaction followed by the dimerization of product, Electrochimica Acta, 90 (2013), pp. 226-231.

[45] N. Fatouros, D. Krulic, Conditions for a nearly perfect match between pulse voltammetry and linear scan voltammetry, Journal of Electroanalytical Chemistry, 817 (2018), pp. 167-175. 
[46] J. M. Olmos, A. Molina, E. Laborda, F. MartínezOrtiz, Effects of unequal diffusion coefficients and coupled chemical equilibria on square wave voltammetry at disc and hemispherical microelectrodes, Electrochimica Acta, 176 (2015), pp. 1044-1053.

[47] S. N. Vettorelo, F. Garay, Theory of square-wave catalytic adsorptive stripping voltammetry. How to obtain mechanistic information from experimental data, Journal of Electroanalytical Chemistry, 826 (2018), pp. 125-132.

[48] N. Meddings, J. R. Owen, N. Garcia-Araez, A simple, fast and accurate in-situ method to measure the rate of transport of redox species through membranes for lithium batteries, Journal of Power Sources, 364 (2017), pp. 148-155.

[49] Parveen, R. Kant, General theory for pulse voltammetric techniques at rough electrodes: multistep reversible charge transfer mechanism, Electrochimica Acta, 220 (2016), pp. 475-485.

[50] L. Shaw, L. Dennany, Applications of electrochemical sensors: Forensic drug analysis, Current Opinion in Electrochemistry, 3 (2017), pp. 23-28.

[51] V. Jovanovski, S. B. Hočevar, B. Ogorevc, Bismuth electrodes in contemporary electroanalysis, Current Opinion in Electrochemistry, 3 (2017), pp. 114 122.

[52] Y. Liu, Y. Liu, L. Qiao, Y. Liu, B. Liu (in press), Advances in signal amplification strategies for electrochemical biosensing, Current Opinion in Electrochemistry. DOI: 10.1016/j.coelec.2018.05.001

[53] J. Hoyos-Arbeláez, M. Vázquez, J. ContrerasCalderón, Electrochemical methods as a tool for determining the antioxidant capacity of food and beverages: A review, Food Chemistry, 221 (2017), pp. 1371-1381.

[54] S. Huang, N. Gan, T. Li, Y. Zhou, Y. Cao, Y. Dong, Electrochemical aptasensor for multiantibiotics detection based on endonuclease and exonuclease assisted dual recycling amplification strategy, Talanta, 179 (2018), pp. 28-36.

[55] X. Cao, J. X. Liu, F. Zhang, Z. Wang, H. Liu, L. $\mathrm{Lu}, \mathrm{A}$ new dual-signalling electrochemical aptasensor with the integration of "signal on/off" and "labeling/label-free" strategies, Sensors and Actuators B: Chemical, 239 (2017), pp. 166-171.

[56] K. Biała , A. S. Mix, K. Bär, P. Orsag, M. Fojta, G. Flechsig, Amplified detection of single base mismatches with the competing-strand assay reveals complex kinetic and thermodynamic behavior of strand displacement at the electrode surface, Electrochimica Acta, 285 (2018), pp. 272-283

[57] N. Tonello, M. B. Moressi, S. N. Robledo, F. D'Eramo, J. M. Marioli, Square wave voltammetry with multivariate calibration tools for determination of eugenol, carvacrol and thymol in honey, Talanta, 158 (2016), pp. 306-314

[58] A. Taleb, X. Yanpeng, P. Dubot, Self-organized gold nanoparticles modified HOPG electrodes: Electrochemical stability and its use for electro- chemical nanosensing applications, Applied Surface Science, 420 (2017), pp. 110-117.

[59] G. D. da Silveira, L. M. de Carvalho, N. Montoya, A. Domenech-Carbó, Solid state electrochemical behavior of organosulfur compounds, Journal of Electroanalytical Chemistry, 806 (2017), pp. 180190.

[60] V. Mirceski, D. Guziejewski, K. Lisichkov, Electrode kinetic measurements with square-wave voltammetry at a constant scan rate, Electrochimica Acta, 114 (2013), pp. 667-673.

[61] D. Guziejewski, V. Mirceski, D. Jadresko, Measuring the electrode kinetics of surface confined electrode reactions at a constant scan rate, Electroanalysis, 27 (2015), pp. 67-73.

[62] V. Mirčeski and M. Lovrić, Split square-wave voltammograms of surface redox reactions, Electroanalysis, 9 (1997), pp. 1283-1287.

[63] V. Mirčeski, S. Smarzewska, D. Guziejewski, Measuring the electrode kinetics of vitamin B2 at a constant time window of a square wave voltammetric experiment, Electroanalysis, 28 (2016), pp. 385-393.

[64] C. Bonazzola , G. Gordillo, Advanced analysis for electrode kinetic studies of surface reactions by applying square-wave voltammetry, Electrochimica Acta, 213 (2016), pp. 613-619.

[65] V. Mirčeski, E. Laborda, D. Guziejewski, R. G. Compton, A new approach to electrode kinetic measurements in square-wave voltammetry. Amplitude-based quasireversible maximum, Anal. Chem. 85 (2013), pp. 5586-5594.

[66] D. Jadreško, M. Zelić, M. Lovrić, A formal scan rate in staircase and square-wave voltammetry, Journal of Electroanalytical Chemistry, $\mathbf{6 4 5}$ (2010), pp. 103-108.

[67] V. Mirčeski, D. Guziejewski, M. Bozem, I. Bogeski, Characterizing electrode reactions by multisampling the current in square-wave voltammetry, Electrochim. Acta, 213 (2016), pp. 520-528.

[68] X. Cheng, G. Pu, Cyclic Square Wave Voltammetry: Theory and Experimental, Anal. Lett., 20 (1987), pp. 1511-1519.

[69] M. A. Mann, L. A. Bottomley, Cyclic Square Wave Voltammetry of Surface-Confined Quasireversible Electron Transfer Reactions, Langmuir, 31 (2015) pp. 9511-9520.

[70] C. J. Helfrick Jr, L. A. Bottomley, Cyclic square wave voltammetry of single and consecutive reversible electron transfer reactions, Anal. Chem., 81, 21 (2009), pp. 9041-9047.

[71] C. John, Helfrick Jr., M. A. Mann, A. Lawrence, Bottomley diagnostic criteria for the characterization of electrode reactions with chemical reactions following electron transfer by cyclic square wave voltammetry, Electrochimica Acta, 205 (2016), pp. 20-28.

[72] A. Molina, M. M. Moreno, C. Serna, M. LopezTenes, J. Gonzalez, N. Abenza, Study of multicen- 
ter redox molecules with square wave voltammetry, J. Phys. Chem. C. 111 (2007), pp. 12446-12453.

[73] M. Zelić, M. Lovrić, Isopotential points in reverse square-wave voltammetry, J. Electroanal. Chem., 637 (2009), pp. 28-32.

[74] M. Lovrić, D. Jadreško, Theory of square-wave voltammetry of quasireversible electrode reactions using an inverse scan direction, Electrochim. Acta, 55 (2010), 948-951.

[75] M. Lovrić, Š. Komorsky-Lovrić, Theory of reverse scan square-wave voltammetry influenced by the kinetics of reactant adsorption, Cent. Eur. J. Chem. 8 (2010), pp. 513-518.

[76] M. C. Henstridge, E. Laborda, N. V. Rees, R. G. Compton, Marcus-Hush-Chidsey theory of elec- tron transfer applied to voltammetry: A review, Electrochim. Acta, 84 (2012), pp. 12-20.

[77] D. Jadreško, D. Guziejewski, V. Mirčeski, Electrochemical Faradaic Spectroscopy, Chem. ElectroChem, 5 (2018), pp. 187-194.

[78] W. M. Smit, M. D. Wijnen, Square wave electrolysis. I. The cyclic potential-step method, Recueil, 79 (1960), pp. 5-21.

[79] W. M. Smit, M. D. Wijnen, Square wave electrolysis III. Apparatus for the cyclic potential-step and cyclic current-step methods, Recueil, 79 (1960), pp. 203-215.

[80] W. M. Smit, M. D. Wijnen, Square wave electrolysis IV. Results and discussion, Recueil, 79 (1960), pp. 289-312.

\title{
КВАДРАТНО-БРАНОВА ВОЛТАММЕТРИЈА: НАЈНОВИ ДОСТИГАЊА И ПЕРСПЕКТИВИ
}

\author{
Валентин Мирчески ${ }^{1,2}$, Леон Стојанов ${ }^{1}$, Sławomira Skrzypek ${ }^{2}$ \\ ${ }^{1}$ Институт за хемија, Природно-математички факултет, \\ Универзитет „Св. Кирил и Методиј“,Скопје, Република Македонија \\ ${ }^{2}$ Department of Inorganic and Analytical Chemistry, Faculty of Chemistry, \\ University of Lódż, Poland
}

Во овој ревијален труд е даден преглед на најновите достигања на квадратно-брановата волтамметрија, како една од најсофистицираните пулсни волтамметриски техники. Разгледани се најновите теориски трудови, дел од напредните студии за аналитичка примена на техниката, а особен акцент е ставен на неколку нови методолошки концепти како што се методата за мерење на електродна кинетика при константна брзина на промена на потенцијалот, циклична квадратно-бранова волтамметрија, квадратно-брановата волтамметрија со повеќекратно мерење на струјата и електрохемиската Фарадеева спектроскопија. За понатамошно усовршување на техниката предложени се две нови методи, досега непознати во научната литература.

Клучни зборови: квадратно-бранова волтамметрија; електрдони механизми; електродна кинетика 
